\title{
Shear strengthening of reinforced concrete beams using externally-bonded aluminum alloy plates: An Experimental Study

\author{
Jamal A. Abdalla ${ }^{1 *}$, Adi S. Abu-Obeidah ${ }^{2}$, Rami A. Hawileh ${ }^{3}$, Hayder A. Rasheed ${ }^{4}$
}

\begin{abstract}
Recently developed high strength Aluminum Alloys (AA) have desirable characteristics that make them attractive as externally bonded strengthening materials. This paper investigates the potential of using AA plates for shear strengthening of reinforced concrete (RC) beams. Five shear deficient RC beams were externally strengthened using AA plates with different orientations. It is observed that the shear capacity of the strengthened beams has increased in the range of $24 \%-89 \%$ compared to the un-strengthened beam. Shear capacity of the strengthened beams was also predicted using the ACI440, FIB14, TR55 and SMCFT design guidelines with the later one giving the most accurate predictions.
\end{abstract}

Keywords: Aluminum alloy; externally-bonded material; shear deficient beams; FRP.

\section{Introduction}

There is a considerable number of RC structures around the world, that can no longer be considered safe [1], as they deteriorated over the years due to various environmental factors, including carbonation, chloride attack, corrosion, etc. As a result, these structures either need to be replaced, which is costly, or strengthened using new and innovative materials. Also, the increase in live loads due to change in building functionality and traffic load demand on bridges, made it necessary to consider strengthening and retrofitting of such structures. The strengthening

\footnotetext{
${ }^{1}$ Professor, Department of Civil Engineering, American University of Sharjah, UAE.

* corresponding author email:jabdalla@aus.edu

${ }^{2}$ Graduate Student, Department of Civil Engineering, Rutgers, The State University of New Jersey, NJ, USA.

${ }^{3}$ Professor, Department of Civil Engineering, American University of Sharjah, UAE.

${ }^{4}$ Professor, Department of Civil Engineering, Kansas State University, Manhattan, KS, USA.
} 
methods implemented should be simple, effective and economical to be considered as viable option. Strengthening of shear deficient reinforced concrete beams today are mainly accomplished by externally bonding steel plates or transverse fiber reinforced polymer (FRP) sheets or plates to the web faces of these beams. The choice of FRP sheets and plates in shear strengthening of structural concrete members were investigated by many researchers and proved to be effective [2-20]. Also, the use of steel plates as externally bonded material has proven to be effective as investigated by other researchers [1,21-25].

Alternatively, Aluminum Alloy (AA) has the desirable mechanical properties that can overcome some deficiencies in steel and FRP and qualifies it as a superior external strengthening material. As a result, this study is mainly focused on experimentally investigating the potential of using aluminum alloys as externally bonded strengthening material. The recently developed aluminum alloys possess desirable characteristics that can overcome the deficiencies in steel and FRP. These alloys are economical, effective and easy to install as demonstrated by a preliminary study conducted by the authors [26-28] to proof the concept. To the best of the authors' knowledge, the use of AA plates as externally bonded strengthening material has not been investigated, yet. Therefore, the significance of this research is to investigate the feasibility and the effectiveness of using AA plates in external shear strengthening of deficient reinforced concrete beams

\section{Background}

A brief background of the experimental investigations in shear strengthening of RC beams using FRP and steel is given below, along with an introduction of the superior advantages of using AA plates. 
Published in Construction and Building Materials, Vol. 128, 2016, pp. 24-37.

\subsection{Shear Strengthening using FRP}

In the last two decades, extensive research on shear strengthening of $\mathrm{RC}$ beams using externally bonded CFRP and GFRP composite materials have been conducted by many researchers $[2,6,11-13,15,29-31]$. The shear strengthening methods employed, involve side bonding of sheets or plates and U-wrapping of sheets at different orientations and configurations. The results showed that there is a considerable increase in the shear capacity of deficient beams exceeding 90\% [29]. Hawileh et al. [32, 33] and Nawaz et al. [34] investigated the effect of longitudinal flexural reinforcement of CFRP sheets and plates on shear capacity of RC beams. They concluded that the increase in the capacity of the specimens strengthened with longitudinal CFRP sheets was in the range of $10 \%$ to $70 \%$ [32] and for those strengthened with longitudinal CFRP plates was in the range of $13 \%$ to $138 \%$ [34] compared to the control specimens. The effect of U-jacketing or U-wrapping using CFRP and GFRP sheets on shear strengthening of RC beams was also studied by several investigators $[2,6,11,12,16,35-37]$. They concluded that FRP sheet U-Wrapping significantly increases the shear capacity of deficient beams. The U-wrap with end anchorage was shown to be the most effective configuration in increasing shear capacity [6]. Shear strengthening of RC beams subjected to cyclic loading was conducted by Calalillo and Sheikh [14] who concluded that using CFRP sheets was effective in increasing the capacity of the under designed beams in the range of $25 \%$ to $114 \%$.

\subsection{Shear Strengthening using steel plates}

Other researchers have also studied the use of steel plates in shear strengthening of RC beams [1, 22-25, 38]. Adhikary et al. [1] and Adhikary and Mutsuyoshi [23] studied the effect of epoxy-bonded continuous horizontal steel plates with different thickness and width on the shear capacity of beams under-reinforced in shear. They observed that continuous steel plates bonded 
Published in Construction and Building Materials, Vol. 128, 2016, pp. 24-37.

externally to beam webs showed shear strength levels $84 \%$ higher than the respective values of the control beam. In another study, Adhikary and Mutsuyoshi [24] examined the effect of different strengthening schemes and techniques including steel strips, externally anchored steel stirrups, small plates of steel and steel brackets on the under-reinforced shear capacity improvements. They observed that epoxy bonded steel plates provided around $72 \%$ increase in shear capacity, while beams with externally anchored stirrups yielded $117 \%$ increase in shear capacity compared to the control beam. Barnes et al. [22] tested several beams to investigate the effect of externally bonded and anchored steel plates in the shear capacity improvement of RC beams. They investigated different (a) plate thicknesses, (b) shear span-to-depth ratios and (c) connections to the beam's side surfaces. The ultimate capacity of the beams with bonded plate was increased up to $90 \%$ compared to the control beam. Altin et al. [38] investigated the effect of side bonded steel plates on the shear capacity of RC T-beams. All the plates were bonded using epoxy adhesive along the shear span of the beam web. The results showed that the externally bonded steel plates improved beams strength, stiffness and ductility. The increase in the shear capacity of the RC beams ranged between $88 \%$ and $98 \%$ of the control beam. Barnes and Mays [25] tested several R/C rectangular beams and T- beams strengthened with steel plates and steel links bonded with epoxy adhesive. The increase in the shear capacity of the rectangular beams ranged between $30 \%$ and $194 \%$ and for the T-beams from 5\% up to $88 \%$.

\subsection{Aluminum Alloys}

Although FRP and steel materials have proven to be very effective in shear strengthening of RC beams, however, they have their unavoidable shortcomings. For instance, the disadvantages of using steel plates as externally bonded material are their low corrosion resistance, heavy weight and the need for coating and painting that result in high maintenance 
Published in Construction and Building Materials, Vol. 128, 2016, pp. 24-37.

cost [39]. Also, the weaknesses of FRP materials are their low thermal resistance, brittle behavior with no well-defined yield point and the unidirectional properties that limit their use. Recently developed high strength aluminum alloys are some of the most promising metals that can be bonded externally to structural elements and contribute significantly in increasing their load carrying capacity while overcoming some of the drawbacks of using FRP and steel. Some of the desirable characteristics and compelling reasons for using aluminum alloys in particular as externally bonded strengthening material are their high strength to weight ratio, high ductility, high corrosion resistance, high thermal resistance and their reasonable cost. Aluminum is an isotropic material that is easy to form and easy to bond to RC surface using epoxy with or without mechanical anchorages.

Until recently, aluminum alloys are used predominantly in the aerospace industry and in ship-buildings. In recent years, aluminum alloys found applications in pedestrian bridges and in some light structures. The recent development of high strength aluminum alloys $[40,45]$ and the reduction in cost have encouraged structural engineers to consider aluminum alloy in several other applications.

There are different types of aluminum alloy materials that belong to eight different series (1000 -8000 series). The 5000 series (e.g., 5083 and 5086) are called marine grade aluminum alloy. These are mainly used in ship-buildings and pressure vessels and they are available in sheet forms. Their ultimate tensile strength ranges between 275 - $350 \mathrm{MPa}$. The 6000 series, e.g., 6061, 6063 and 6082 are called structural aluminum alloy and are used for structural components. Their ultimate strength reaches $300 \mathrm{MPa}$. The 7000 series, e.g., 7068, 7075 are of high strength and are used in aircraft and aerospace industries. Their ultimate tensile strength reaches $570 \mathrm{MPa}$. In addition, the newly developed 2000 series (e.g., 2524, 2224), 7000 series 
Published in Construction and Building Materials, Vol. 128, 2016, pp. 24-37.

(e.g., 7475, 7055) and new generation aluminum-lithium (Al-Li) alloys (e.g., 2050, 2099) [4045] with high tensile strength, among other desirable characteristics, are very promising as externally bonded strengthening materials [46].

The material used in this investigation is annealed wrought AA5083-0, available in sheets and plates, and has been selected for its exceptional performance in extreme environments [45], such as seawater and industrial chemicals. Furthermore, it has the highest strength among the non-heat treatable alloys. The chemical composition, physical and mechanical properties of AA5083-0 are shown in Table 1. This type of aluminum alloy is typically used in shipbuilding, rail cars, vehicle and truck bodies, dump truck boxes, storage tanks and pressure vessels [45]. AA5083-0 ultimate tensile strength ranges between 290-294 MPa, its tensile yield strength ranges between $145-147 \mathrm{MPa}$, its modulus of elasticity is $70 \mathrm{GPa}$ and its elongation at break is around $22 \%$.

Table 1 Chemical composition, physical and mechanical properties of 5083-0 AA [45]

\begin{tabular}{l|l||l|r|}
\hline \hline \multicolumn{2}{c||}{ Chemical Composition } & \multicolumn{2}{c|}{ Physical and Mechanical Properties } \\
\hline \hline Chemical element & \% Present & Property & Value \\
\hline \hline Aluminum, $\mathrm{Al}$ & $92.4-95.6 \%$ & Density & $2.65 \mathrm{~g} / \mathrm{cm}^{\mathbf{3}}$ \\
\hline Chromium, $\mathrm{Cr}$ & $0.05-0.25$ & Melting Point & $570{ }^{\circ} \mathrm{C}$ \\
\hline Copper, $\mathrm{Cu}$ & $\leq 0.1 \%$ & Thermal Expansion & $72 \mathrm{GPa}$ \\
\hline Iron, $\mathrm{Fe}$ & $\leq 0.4 \%$ & Modulus of Elasticity & $10^{-6} / \mathrm{K}$ \\
\hline Magnesium, $\mathrm{Mg}$ & $4-4.9 \%$ & Thermal Conductivity & $0.058 \times 10^{-6} \Omega . \mathrm{m}$ \\
\hline Manganese, $\mathrm{Mn}$ & $0.4-1 \%$ & Electrical Resistivity & $145 \mathrm{MPa}$ \\
\hline Others, each & $\leq 0.05 \%$ & Proof Stress & $300 \mathrm{MPa}$ \\
\hline Others, total & $\leq 0.15 \%$ & Tensile Strength & $23 \%$ \\
\hline Silicon, $\mathrm{Si}$ & $\leq 0.40 \%$ & Elongation A50 mm & $175 \mathrm{MPa}$ \\
\hline Titanium, $\mathrm{Ti}$ & $\leq 0.15 \%$ & Shear Strength & $75 \mathrm{HV}$ \\
\hline Zinc, $\mathrm{Zn}$ & $\leq 0.25 \%$ & Hardness Vickers & \\
\hline \hline
\end{tabular}




\section{Experimental Program}

\subsection{Materials and Material tests}

\subsubsection{Concrete}

Ready-mixed concrete was used to cast all specimens. Concrete cubes of $150 \mathrm{~mm}$ x $150 \mathrm{~mm}$ $\mathrm{x} 150 \mathrm{~mm}$ were made from the same batch on site and tested to determine the compressive strength of the concrete. The cubes were tested after 28 days and the average compressive strength of the concrete cubes was found to be equal to $37.2 \mathrm{MPa}$ (equivalent to cylinder strength of around $29.76 \mathrm{MPa}$ ).

\subsubsection{Steel Bar Reinforcement}

To determine the mechanical properties of reinforcing steel used in this study, three steel reinforcing bars were tested under uniaxial tension. The total length of the specimens was 300 $\mathrm{mm}$ with a gauge length of $100 \mathrm{~mm}$. The obtained results for the elastic modulus $\left(E_{s}\right)$, yield strength $\left(f_{y}\right)$, and tensile strength $\left(f_{u}\right)$ are presented in Table 2. Fig. 1 shows the stress-strain curves of the tested specimens.

Table 2 Steel reinforcements bars properties

\begin{tabular}{cccc}
\hline \hline & $E_{s}(\mathrm{GPa})$ & $f_{y}(\mathrm{MPa})$ & $f_{u}(\mathrm{MPa})$ \\
\hline \hline Specimen\#1 & 199.99 & 588.5 & 694.0 \\
\hline \hline Specimen\#2 & 199.97 & 587.4 & 698.8 \\
\hline Specimen\#3 & 200.00 & 595.05 & 711.3 \\
\hline Average & $\mathbf{1 9 9 . 9 9}$ & $\mathbf{5 9 0 . 3 6}$ & $\mathbf{7 0 1 . 4 0}$ \\
\hline
\end{tabular}




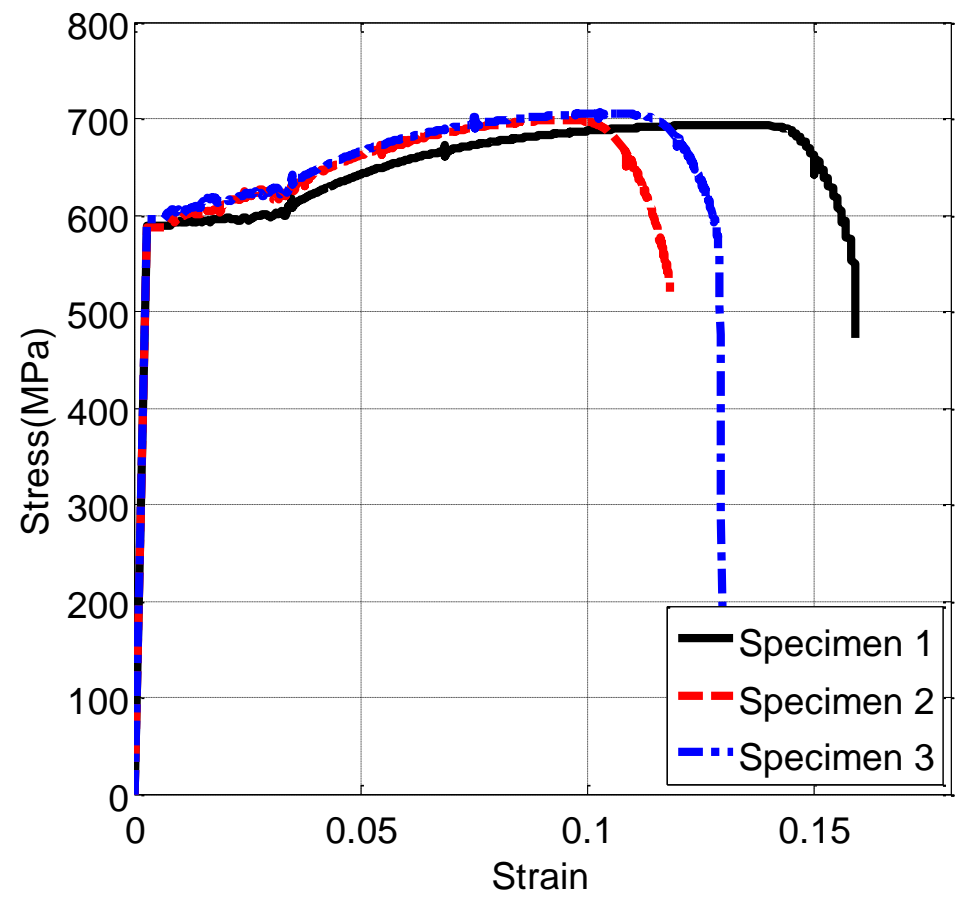

Fig. 1. Test results of steel reinforcement

\subsubsection{AA5083-0 Plates}

To determine the mechanical properties of AA5083-0 used in this study, three specimens were shaped as a dogbone coupon and tested using ASTM B928/B928M [47] standard specifications for high Magnesium Aluminum-Alloy sheet and plate for Marine service and similar environments. As shown in Fig. 2, the plates were machined to enforce failure in the specimen away from the grips. The specimens were prepared according to the ASTM standards [47]. Each coupon specimen had a total length of $300 \mathrm{~mm}$, width of $45 \mathrm{~mm}$, radius of fillet of $12.5 \mathrm{~mm}$, grip length of $50 \mathrm{~mm}$, and a gauge length of $100 \mathrm{~mm}$ as shown in Fig. 2a. Fig. 2b shows the test setup in a $100 \mathrm{kN}$ Universal Testing Machine (UTM) that has gripped the specimen from both sides. Fig. $2 \mathrm{c}$ and Fig. $2 \mathrm{~d}$ show the three prepared specimens that are labeled as A1, A2 and A3 before and after testing, respectively. The failure plane of the three specimens occurred within the gauge length (i.e., machined part). 
Published in Construction and Building Materials, Vol. 128, 2016, pp. 24-37.

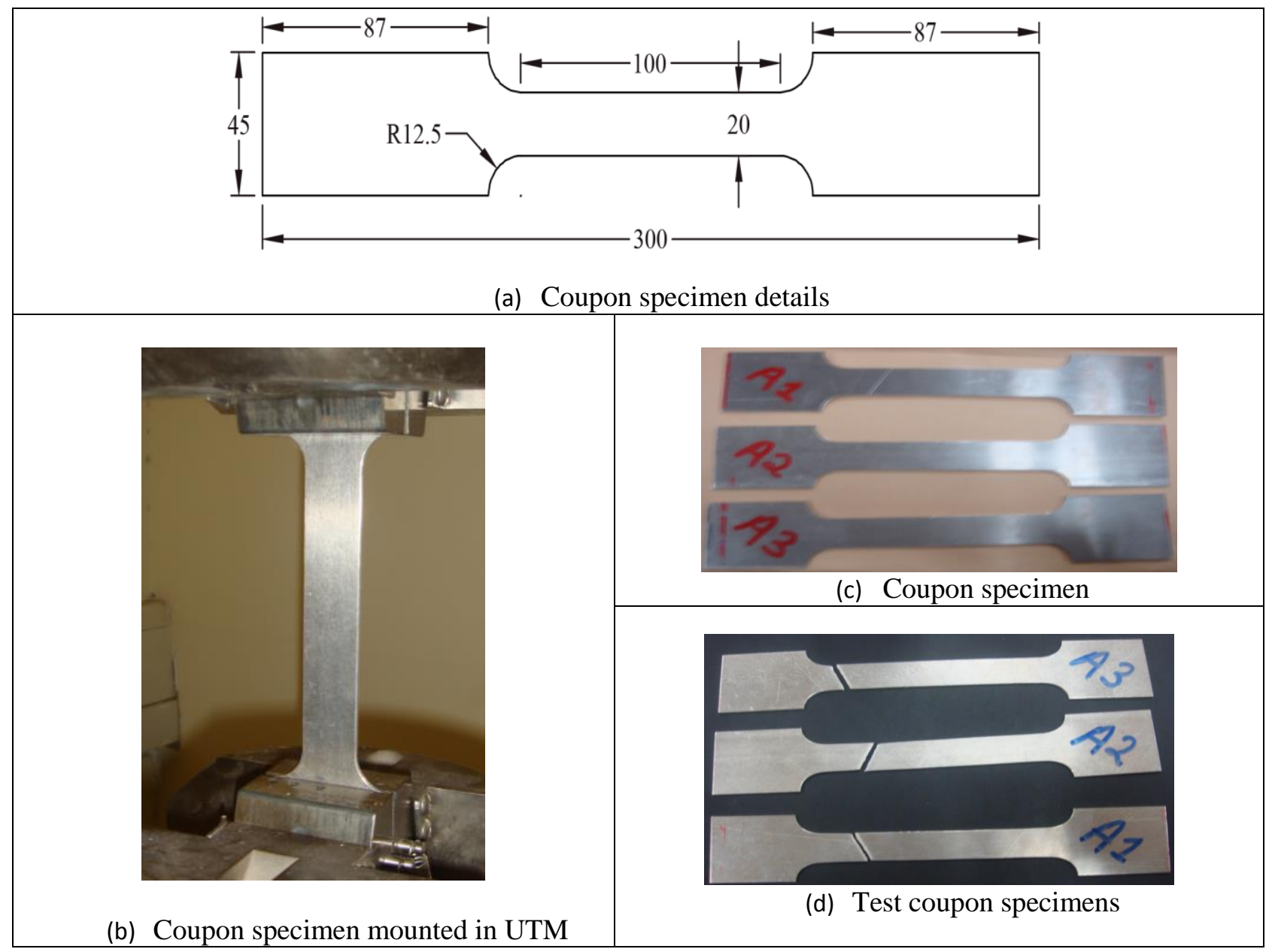

Fig. 2. Coupon test of aluminum alloy specimens

Fig. 3 and Table 3 present the tensile test results for the three AA5083-0 specimens. The measured average yield strength was $146.3 \mathrm{MPa}$, the measured average ultimate strength was $293 \mathrm{MPa}$ and the measured average elongation at break was $24.3 \%$ which are in close agreement with those of the manufacturer's specifications [45]. 


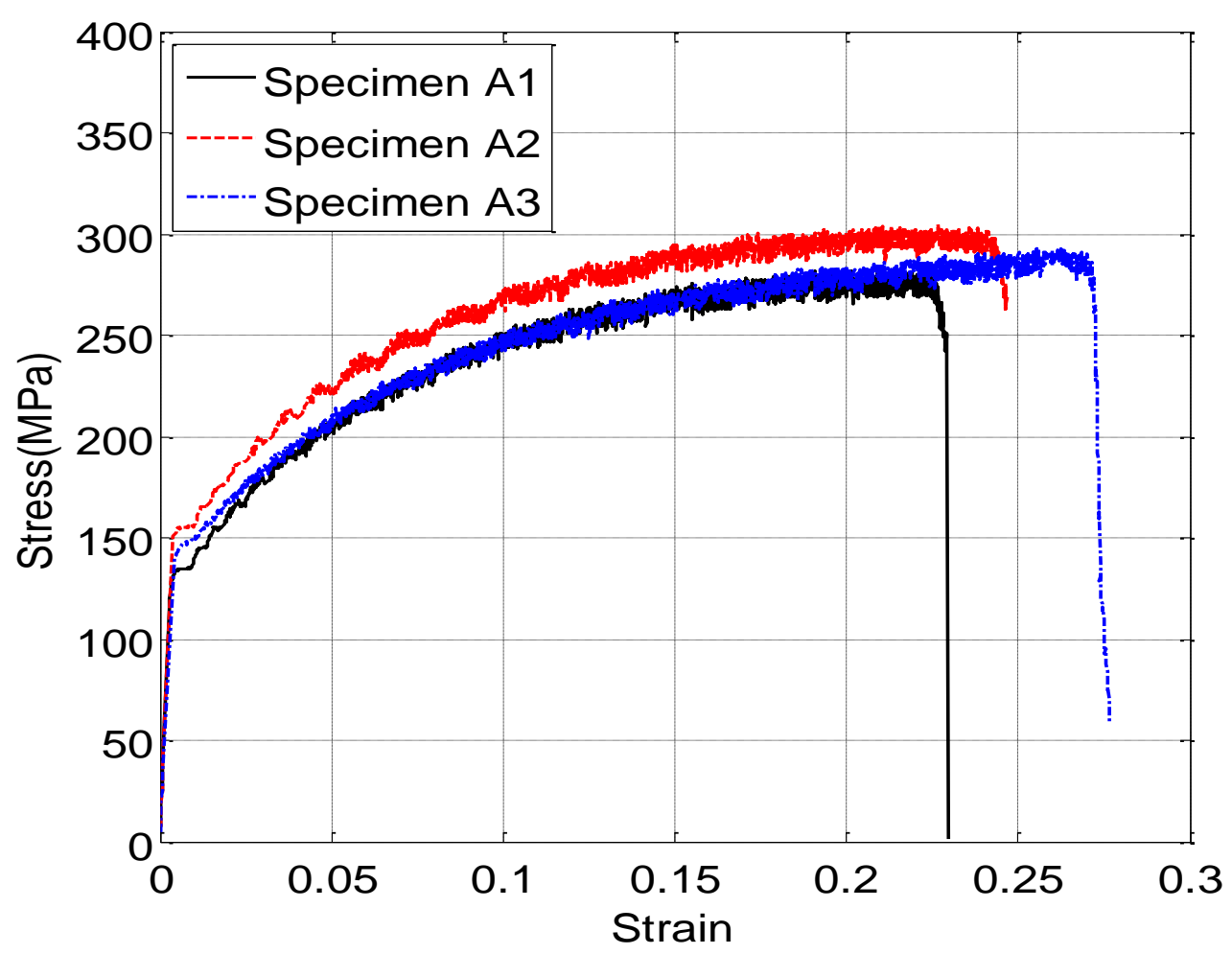

Fig. 3. Stress-strain curve of the tested AA5083-0 specimens

Table 3 Mechanical properties of the tested AA5083-0 specimens

\begin{tabular}{lcccc}
\hline \hline & $\begin{array}{c}E_{A A} \\
(\mathrm{GPa})\end{array}$ & $\begin{array}{c}f_{y} \\
(\mathrm{MPa})\end{array}$ & $\begin{array}{c}f_{u} \\
(\mathrm{MPa})\end{array}$ & $\begin{array}{c}\text { Elongation } \\
(\%)\end{array}$ \\
\hline Specimen A1 & - & 141 & 281.87 & 22.34 \\
\hline Specimen A2 & - & 150 & 304.42 & 23.94 \\
\hline Specimen A3 & - & 148 & 292.78 & 26.71 \\
\hline Average of tests & - & 146.3 & 293.0 & 24.3 \\
\hline Specifications & 70 & 145 & 295 & 22 \\
\hline \hline
\end{tabular}

\subsubsection{Epoxy}

Sikadur-30LP [48] is the epoxy resin adhesive used in this study to bond the AA plates to the concrete surfaces. It is solvent-free, structural two-part adhesive (part A and part B) that has been designed for use at temperatures between $25^{\circ} \mathrm{C}$ and $45^{\circ} \mathrm{C}$ for bonding structural strengthening reinforcements. It is easy to mix and easy to apply, doesn't require primer installation and is suitable for dry and damp concrete surfaces. To create the adhesive mix, part 
A and part B needed to be mixed in a ratio of 3:1 continuously for a 3-4 minute period until a light grey color emerged. After getting the light grey color, the epoxy must be used within 45 minutes which is the time needed to dry. After a curing time of 7-14 days in a room temperature of $25^{\circ} \mathrm{C}$, the modulus of elasticity, compressive strength, flexure strength and shear strength of the cured epoxy were $10 \mathrm{GPa}, 85 \mathrm{MPa}, 25 \mathrm{MPa}$, and $17 \mathrm{MPa}$, respectively. The epoxy had a density of $1.8 \mathrm{~kg} / \mathrm{ltr}+/-0.01 \mathrm{~kg} / \mathrm{ltr}$ and its measured thickness is usually between $1-3 \mathrm{~mm}$. Its hardening is not affected by high relative humidity, and it is impermeable to liquids and water vapor. To ensure the maximum bond strength, concrete surface and aluminum plates were all grinded to achieve adequate bond strength between them. Table 4 summarizes some of the physical and mechanical properties of the epoxy as reported by the manufacturer [48].

Table 4 Technical data of Sikadur-30 LP CFRP laminate (plate) epoxy [48]

\begin{tabular}{ll}
\hline \hline Property & Description (value or range) \\
\hline \hline $\begin{array}{l}\text { Appearance and } \\
\text { colors }\end{array}$ & Resin part A: white, Resin part B: black \\
& Part A+B mixed: light grey \\
\hline Service temperature & $-40^{\circ} \mathrm{C}$ to $+45^{\circ} \mathrm{C}\left(\right.$ when cured at $\left.>+23^{\circ} \mathrm{C}\right)$ \\
\hline Density & $1.65 \mathrm{~kg} / \mathrm{ltr}+0.1 \mathrm{~kg} / \mathrm{ltr}\left(\right.$ parts $\mathrm{A}+\mathrm{B}$ mixed at $\left.+23^{\circ} \mathrm{C}\right)$ \\
\hline Tensile strength & 15 to $18 \mathrm{MPa}\left(7\right.$ days curing time at $\left.+25^{\circ} \mathrm{C}\right)$ \\
\hline Flexural strength & $>25 \mathrm{MPa}\left(7\right.$ days curing time at $\left.+25^{\circ} \mathrm{C}\right)$ \\
\hline Compressive strength & $>85 \mathrm{MPa}\left(3\right.$ days curing time at $\left.+25^{\circ} \mathrm{C}\right)$ \\
\hline Bond strength & Concrete fracture $(>4 \mathrm{MPa})$ on sand-blasted substrate: $>1$ day \\
\hline Shear strength & $7 \mathrm{MPa}\left(7\right.$ days curing time at $\left.+25^{\circ} \mathrm{C}\right)$ \\
\hline Change of volume & Shrinkage: $0.04 \%$ \\
\hline Thermal stability & Heat Distortion Temperature $(\mathrm{HDT}):+47^{\circ} \mathrm{C}\left(7\right.$ days at $\left.+23^{\circ} \mathrm{C}\right)$ \\
\hline E-modulus & Compression: $10 \mathrm{GPa}\left(7\right.$ days at $\left.+25^{\circ} \mathrm{C}\right)$ \\
\hline Mixing & Tensile: $10 \mathrm{GPa}\left(7\right.$ days at $\left.+25^{\circ} \mathrm{C}\right)$ \\
\hline \hline
\end{tabular}

Table 5 provides a summary of the average values of the important mechanical material 
Published in Construction and Building Materials, Vol. 128, 2016, pp. 24-37.

properties of concrete, steel reinforcement, AA, and epoxy used and explained earlier in the experimental program of this study.

Table 5 Summary of mechanical material properties

\begin{tabular}{cc|cc|ccccc|cc}
\hline \hline \multicolumn{2}{c|}{ Concrete } & \multicolumn{2}{c|}{ Steel } & \multicolumn{5}{c|}{ AA5083-0 } & \multicolumn{2}{c}{ Epoxy } \\
\hline \hline $\begin{array}{c}f_{c u} \\
(\mathrm{MPa})\end{array}$ & $\begin{array}{c}E_{c} \\
(\mathrm{GPa})\end{array}$ & $\begin{array}{c}f_{y} \\
(\mathrm{MPa})\end{array}$ & $\begin{array}{c}E_{c} \\
(\mathrm{GPa})\end{array}$ & $\begin{array}{c}E_{A A} \\
(\mathrm{GPa})\end{array}$ & $\begin{array}{c}\varepsilon_{A A} \\
(\%)\end{array}$ & $\begin{array}{c}f_{y} \\
(\mathrm{MPa})\end{array}$ & $\begin{array}{c}f_{t} \\
(\mathrm{MPa})\end{array}$ & $\begin{array}{c}\text { Thicknes } \\
s(\mathrm{~mm})\end{array}$ & $\begin{array}{c}E_{E} \\
(\mathrm{GPa})\end{array}$ & $\begin{array}{c}f_{t} \\
(\mathrm{MPa})\end{array}$ \\
\hline 37.2 & 28.7 & 590.4 & 200 & 70 & 24.3 & 147 & 293 & 2.0 & 10 & 30 \\
\hline \hline
\end{tabular}

\subsection{Specimens details and testing procedure}

\subsubsection{Specimens' details}

In this study, six shear-deficient reinforced concrete beams were designed, fabricated and tested. Five of these beams were strengthened by externally bonding $2 \mathrm{~mm}$-thick AA plates to the web sides. The dimensions and reinforcement details of the control beam (un-strengthened specimen) are shown in Fig. 4. Each beam specimen has a total depth of $250 \mathrm{~mm}$, width of $150 \mathrm{~mm}$, total length of $1840 \mathrm{~mm}$ and a clear span length of $1690 \mathrm{~mm}$. Four point bending was the loading protocol that was monotonically used to failure. The shear span region was extended for $563 \mathrm{~mm}$ from each support. The beams were cast with no stirrups in the shear span to ensure shear failure of the tested specimens. Four $\varnothing 8 \mathrm{~mm}$ stirrups were provided only in the constant moment region to easily manufacture the steel cage and also to avoid any stress concentration in the concrete under the loading points (Fig. 4b). All beams were reinforced in flexure with $2 \varnothing 16 \mathrm{~mm}$ bars with a concrete cover of $42 \mathrm{~mm}$. In the compression zone, the beams were reinforced with $2 \varnothing 10 \mathrm{~mm}$ bars. Five beams were strengthened in shear using $2 \mathrm{~mm}$ thick AA plates (AA5083-0) that were installed on both web sides. The AA plates were bonded on the sides of both shear span regions with different orientations to act as the only shear reinforcement for the beams. Arrangement of the AA plates and the configuration of the strengthening schemes are shown in Fig. 5. 


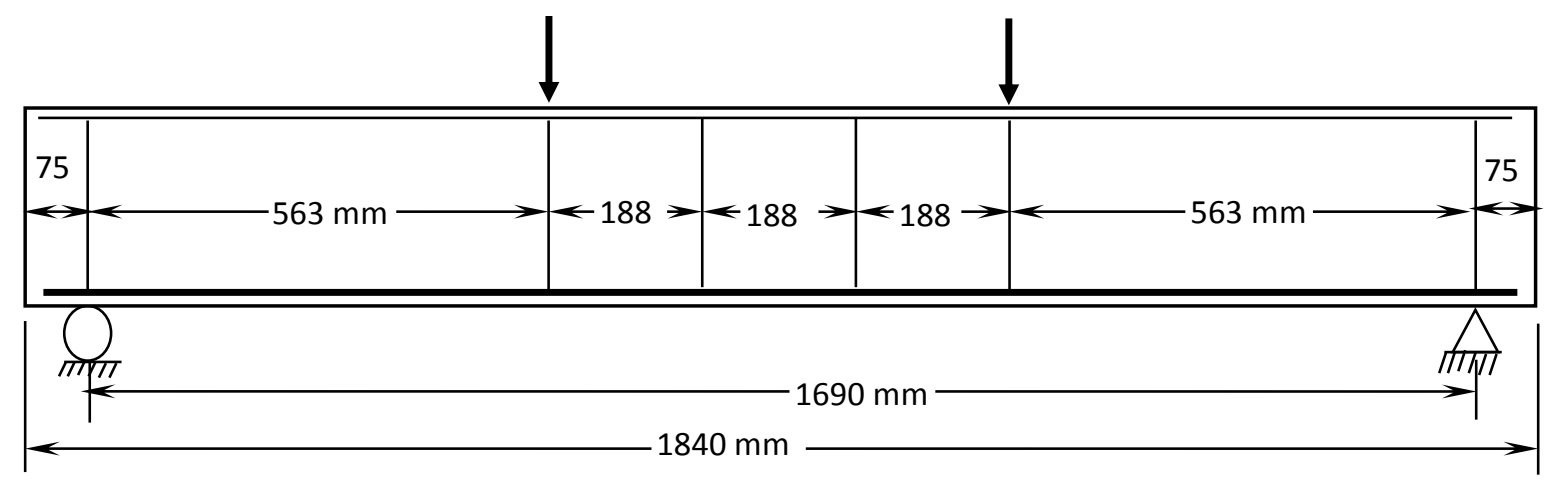

(a)

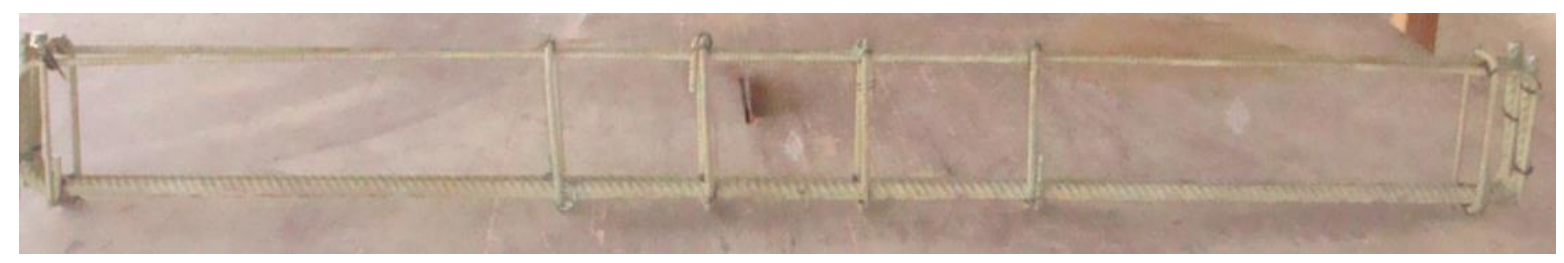

(b)

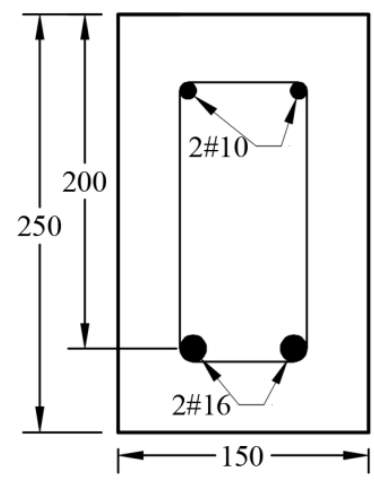

(c)

Fig. 4. Control beam reinforcement profile and cross section

The strengthening procedure of the tested beams included surface preparation by grinding the shear faces of the concrete beam and the back faces of the AA plates with a rotary diamond grinder to create a rough surface and to ensure sufficient bond between them. Once the surface was prepared to the required roughness level, the epoxy resins were applied on both surfaces and the AA plates were pressed in place. Similar strengthening procedure was carried out for all strengthened specimens. 


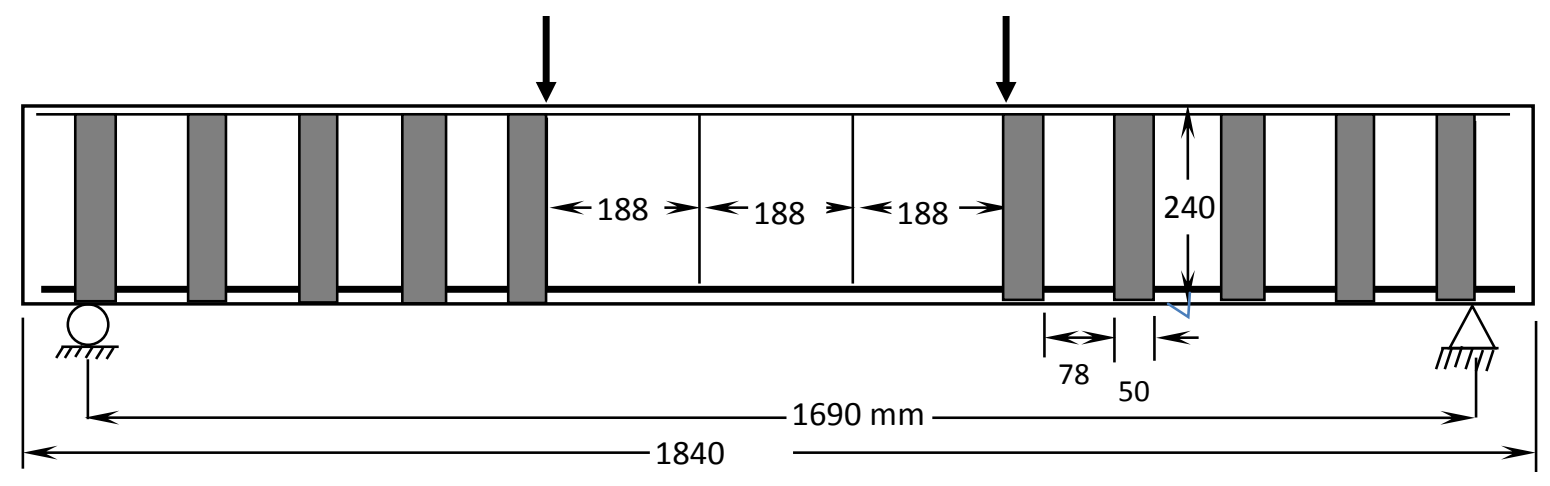

(a)

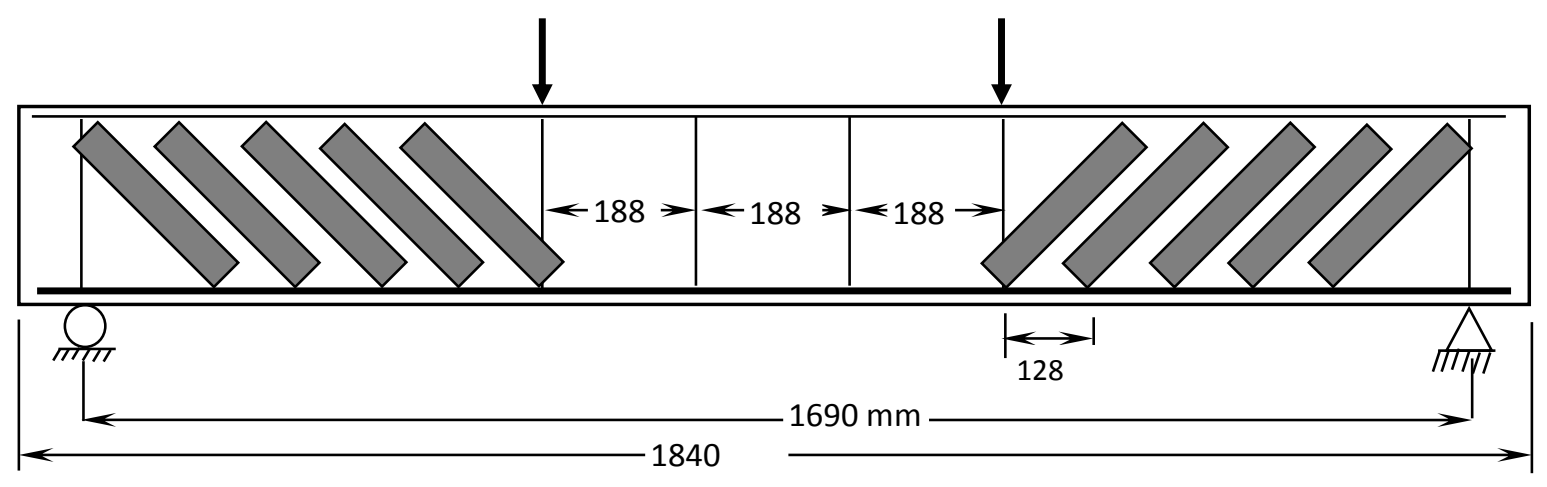

(b)

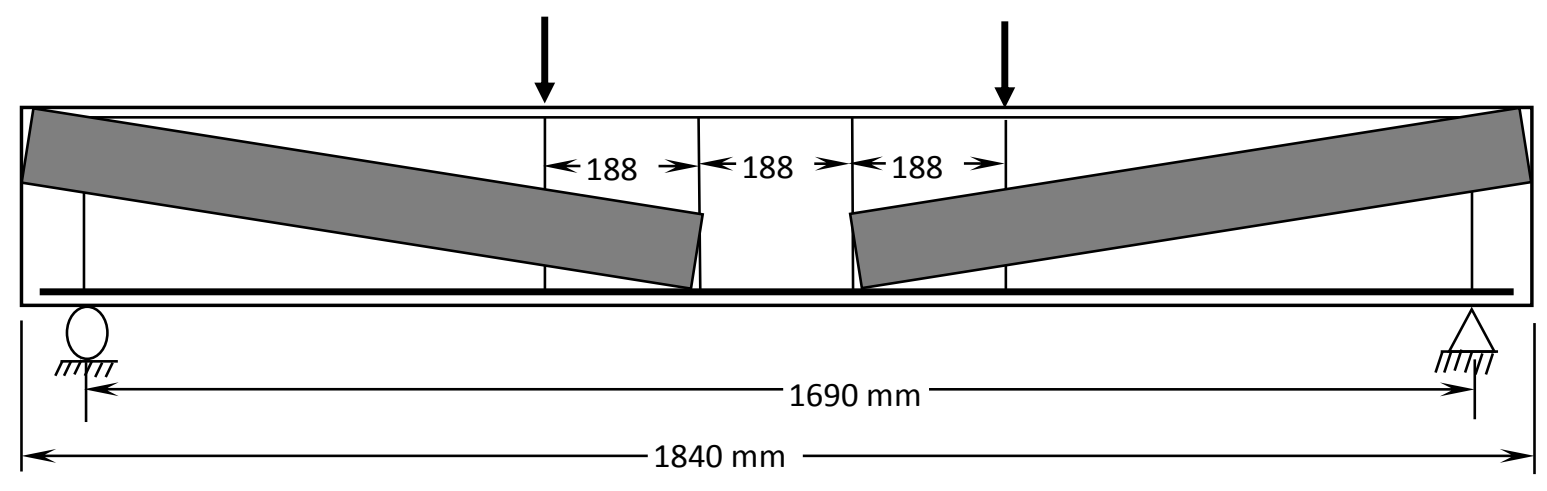

(c)

Fig. 5. Details of the strengthened specimens (AA90, AA45, AADP)

Figs. 5a $-5 \mathrm{c}$ show the three different orientations for the strengthened specimens which are designated as AA90-1, AA90-2, AA45-1, AA45-2 and AADP. AA90 specimens represent beams that were strengthened with $5 \mathrm{~mm}$ x $240 \mathrm{~mm}$ vertical $\left(90^{\circ}\right)$ AA strips spaced at $128 \mathrm{~mm}$ center- 
Published in Construction and Building Materials, Vol. 128, 2016, pp. 24-37.

to-center as shown in Fig. 5a. AA45 specimens represent beams strengthened with the same AA strips used for AA90 beams, bonded at an orientation of $45^{\circ}$ and spaced at $128 \mathrm{~mm}$ center-tocenter as shown in Fig. 5b. Two beams were tested from each of the AA90 and AA45 category. The fifth beam was strengthened with a $10 \mathrm{~mm}$ x $790 \mathrm{~mm}$ AA plate diagonally bonded (AADP) at an angle of $\pm 10^{\circ}$ opposite to the shear crack directions as depicted in Fig. 5c.

\subsubsection{Testing procedure}

The un-strengthened control beam and the five strengthened beams with externally bonded AA plates were all tested under four-point bending monotonically to failure as shown in Figs. 4-5. The control beam was used as a benchmark for comparison with the strengthened beam specimens. The beams were loaded monotonically using, a digitally controlled INSTRON 8806 Universal Testing Machine (UTM), at a rate of $10 \mathrm{kN} / \mathrm{min}$. The loading rate was relatively slow to simulate static loading condition. Foil Strain gauges on some of the aluminum plates were installed to capture the strain response during loading. One strain gauge was installed on the middle plate for the AA90 and AA45 beams from each shear span region and one LVDT was installed at mid-span for all beams to measure deflection. The load was recorded by the UTM machine load cell at 0.1 -second time interval and the corresponding mid-span deflection of the beams was recorded at the same rate using the data acquisition system.

\section{Results and Discussions}

The ultimate load $\left(P_{u}\right)$ and the corresponding ultimate deflection $\left(\delta_{u}\right)$ for all the tested beams have been determined. The test results of all specimens will be discussed in this section with respect to their strength, load-deflection response curves, and failure modes. The obtained experimental results for all the tested specimens are summarized in Table 6 . 
Table 6 Summary of test results and performance comparisons

\begin{tabular}{ccccl}
\hline \hline & $\mathrm{P}_{\mathrm{u}}$ & $\mathrm{P}_{\mathrm{u}} / \mathrm{P}_{\mathrm{uCB}}$ & $\delta_{\mathrm{u}}$ & Failure mode \\
\hline \hline $\mathrm{CB}$ & 60.73 & 1.00 & 4.42 & Shear \\
\hline AA90 - 1 & 106.83 & 1.76 & 7.18 & Shear \\
\hline AA45 - 1 & 75.03 & 1.24 & 6.10 & Shear \\
\hline AA45 - 2 & 96.75 & 1.59 & 9.60 & Shear \\
\hline AADP & 109.55 & 1.80 & 7.53 & $\begin{array}{l}\text { Flexure/ } \\
\text { shear }\end{array}$ \\
\hline \hline
\end{tabular}

\subsection{Control Beam (CB)}

\subsubsection{Strength and load deflection response}

The load versus mid-span deflection response curve for the $C B$ is presented in Fig. 6(a). The ultimate load capacity achieved by the $\mathrm{CB}$ beam was $60.73 \mathrm{kN}$ and the corresponding ultimate deflection $\delta_{\mathrm{u}}$ was $4.42 \mathrm{~mm}$. Based on the flexural capacity equation of ACI 318-14 code, the calculated ultimate load capacity of the control beam is $59.16 \mathrm{kN}$ which is $97 \%$ of the measured experimental value.

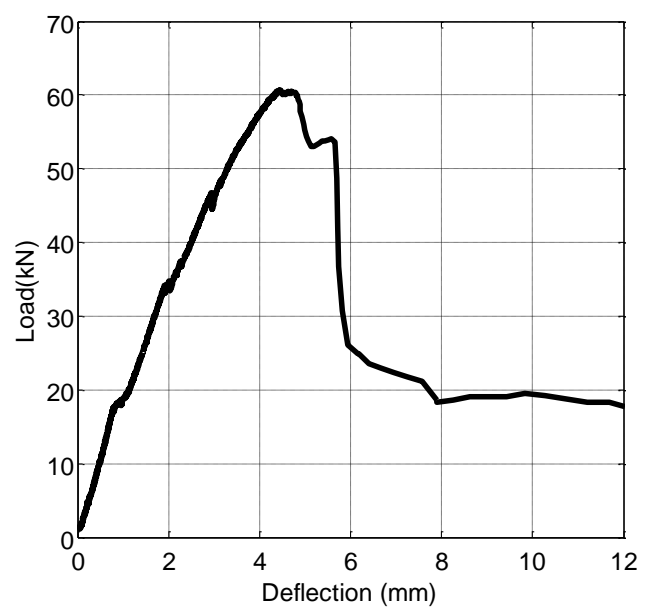

(a) Load-deflection 
Published in Construction and Building Materials, Vol. 128, 2016, pp. 24-37.

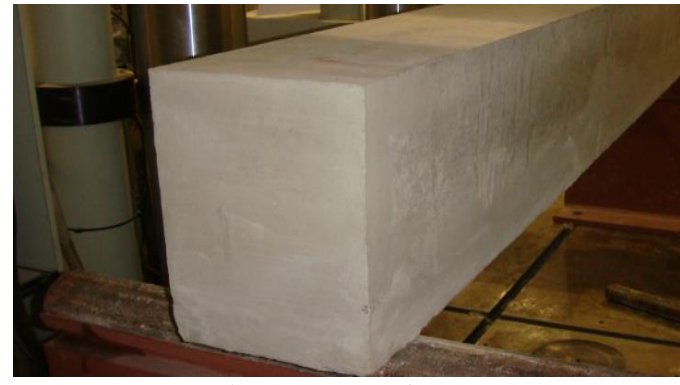

(b) cast specimen

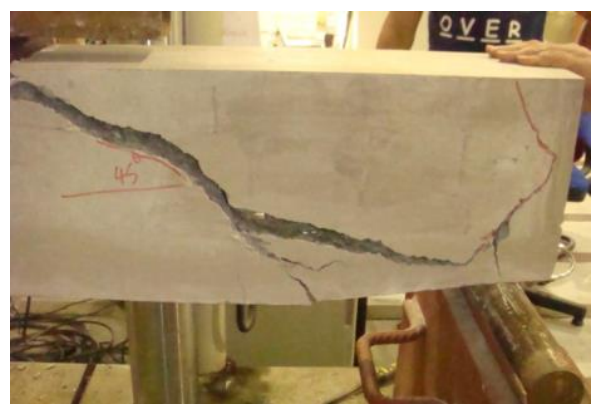

(c) Failure mode

Fig. 6. Control Beam (CB) details and results

\subsubsection{Failure mechanism dicussion}

Fig. 6(b) and Fig. 6(c) show the CB specimen before and after testing, respectively. It is clear that the specimen failed as expected at $\mathrm{P}=60.73 \mathrm{kN}$ by a major shear crack with $45^{\circ}$ inclination. The crack initiated under the loading point and propagated to the edge of the beam near the support.

\subsection{AA90 Beams}

\subsubsection{Strength and Load-deflection response}

Specimens AA90 were tested under four-point bending as shown in Fig. 7(a). The ultimate load capacity of specimens AA90-1 and AA90-2 were $106.83 \mathrm{kN}$ and $75.03 \mathrm{kN}$, respectively as presented in Table 6 and shown in Fig. 7 (b). Thus, there is an increase in the load carrying capacity of the strengthened AA90 beams over the CB specimen by $75.92 \%$ for AA90-1 and 23.5\% for AA90-2. Fig. 7(b) shows the load-deflection response of AA90-1 and AA90-2 tested specimens. It was observed from the load-deflection curve that the deflection at ultimate load of specimen AA90-1 and AA90-2 were $\delta_{\mathrm{u}}=7.18 \mathrm{~mm}$ and $\delta_{\mathrm{u}}=6.10 \mathrm{~mm}$, respectively. 


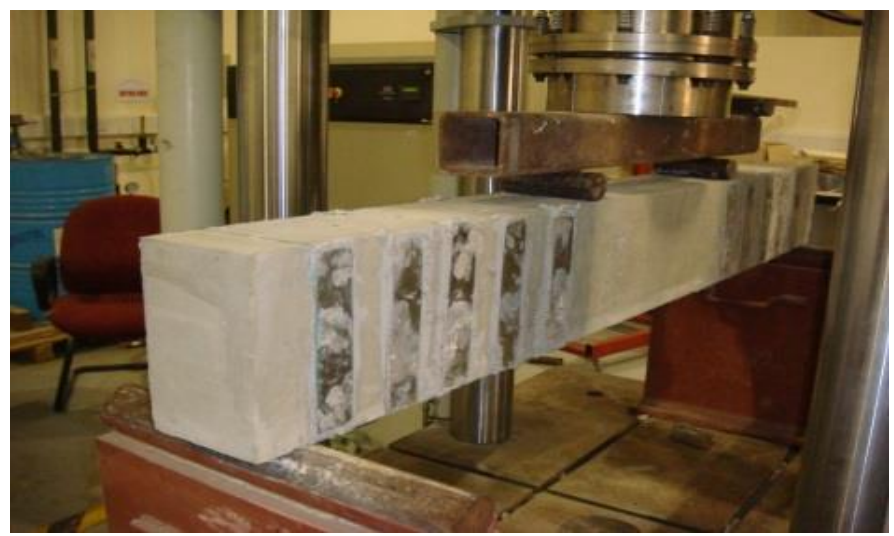

(a) Vertical AA strips - AA90-1 and AA90-2

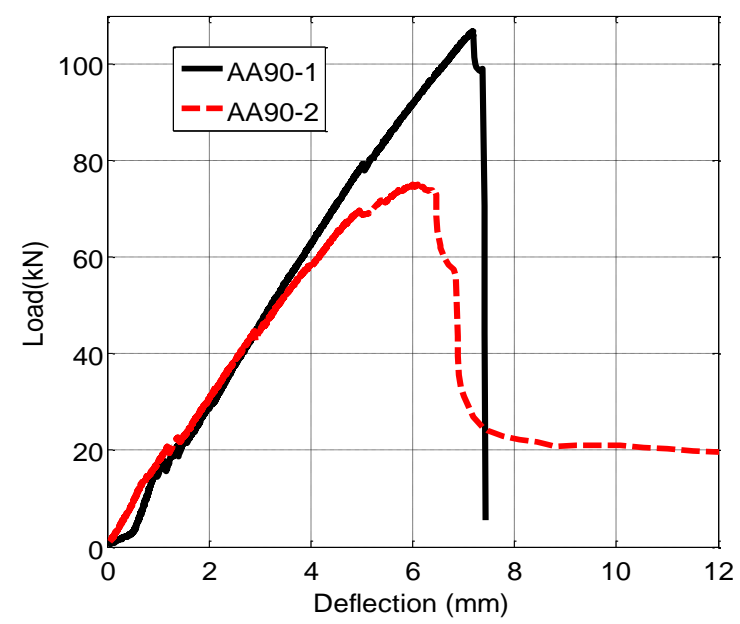

(b) Load-deflection for AA90-1 and AA90-2

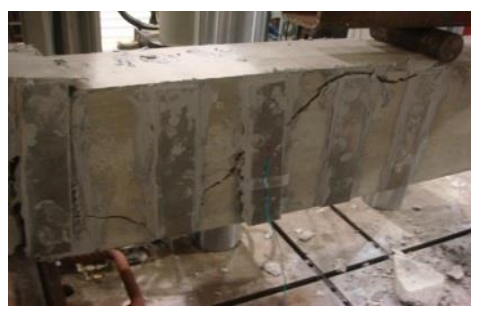

AA90-1

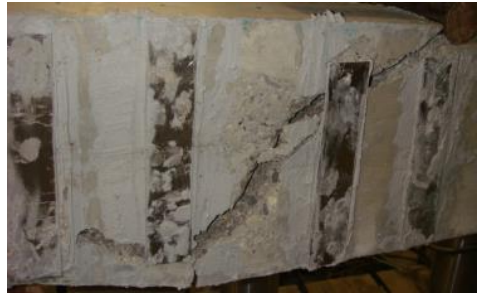

AA90-2

(c) Failure mode - crack at $45^{\circ}$

Fig. 7. Specimens with vertical AA plates (AA90)

\subsubsection{Failure mechanism dicussion}

Both specimens (AA90-1, AA90-2) failed by major shear cracks as shown in Fig. 7(c). In specimen AA90-1, the shear crack started at the point of the application of the load and propagated horizontally above some AA plates and changed to $45^{\circ}$ inclination towards the support as shown in Fig. 7(c). The two AA plates near the loading point captured the shear cracks and forced the crack to take place as horizontal crack above the AA plates which resulted in higher load carrying capacity compared to AA90-2 specimen. AA90-2 failed by a major shear crack at $45^{\circ}$ inclination as expected and it is formed from the point of application of the load to the edge of the beam near the support as shown in Fig.7(c). 
Published in Construction and Building Materials, Vol. 128, 2016, pp. 24-37.

\subsection{AA45 Beams}

\subsubsection{Strength and Load-deflection response}

The ultimate load capacity of specimens AA45-1 and AA45-2 were $114.74 \mathrm{kN}$ and $96.75 \mathrm{kN}$, respectively as shown in Table 6 . Thus, there is an increase in the load carrying capacity of the strengthened AA45 beams over the CB by $88.9 \%$ for AA45-1 and 59.3\% for AA45-2. Fig. 8(a) and 8(c) shows the strengthened specimens before and after testing. The load versus mid-span deflection response of AA45-1 and AA45-2 tested specimens are presented in Fig. 8(b). It was observed from the load-deflection curve of Fig. 8(b) that the deflection at ultimate load of specimen AA45-1 and AA45-2 were $\delta_{\mathrm{u}}=9.80 \mathrm{~mm}$ and $\delta_{\mathrm{u}}=9.60 \mathrm{~mm}$, respectively.

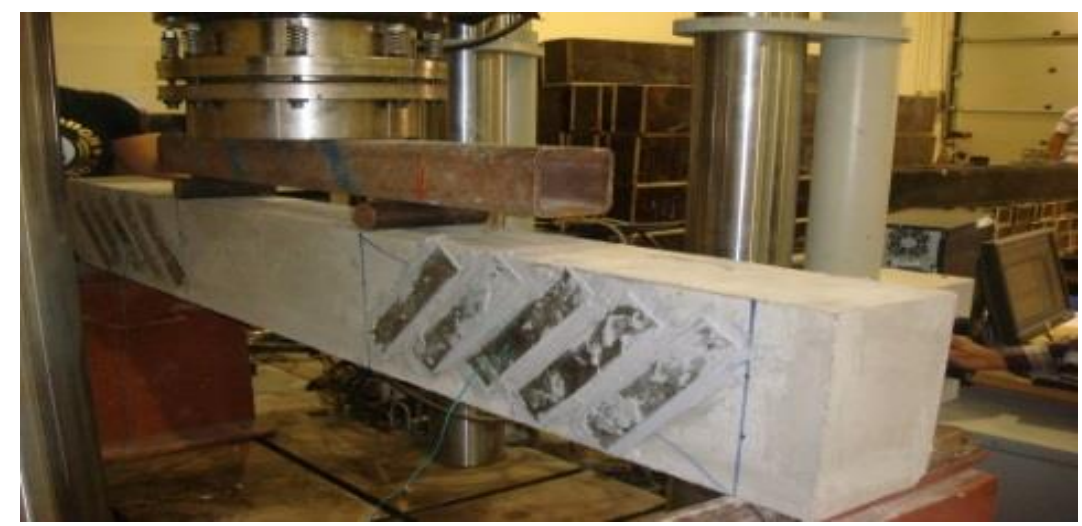

(a) $45^{\circ}$ AA Strips - AA45-1 and AA45-2 


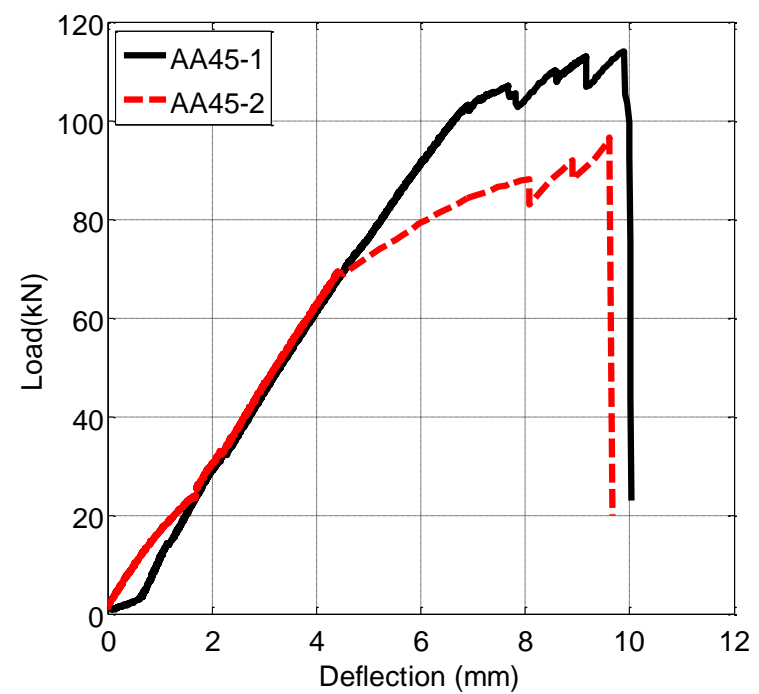

(b) Load-deflection for AA45-1 and AA45-2

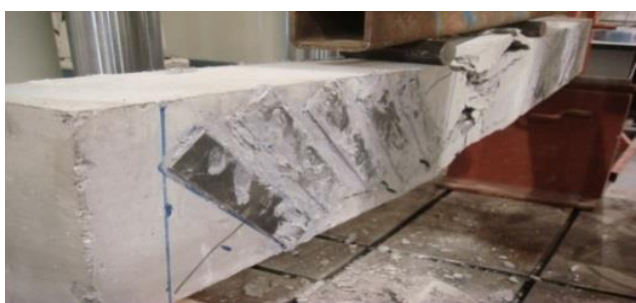

AA45-1

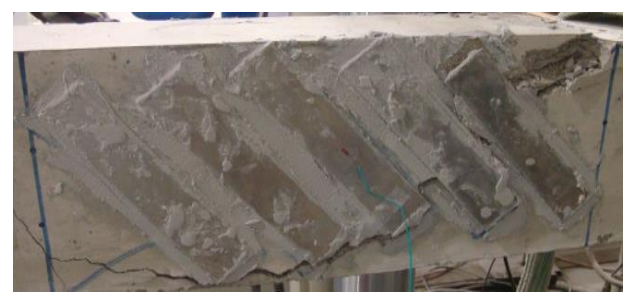

AA45-2

(c) Failure mode - crack at $45^{\circ}$

Fig. 8. Specimens with AA plates at $45^{\circ}$ (AA45)

\subsubsection{Failure mechanism dicussion}

As presented in Fig. 8(c),specimen AA45-1 failure mechanism started with a minor shear crack that initiated at the loading point, and then got blocked by the adjacent AA plates and resulted in crushing of concrete at the compression zone near the loading point. This resulted in higher load carrying capacity compared to AA45-2 as indicated in the load-deflection curve shown in Fig. 8(b). Specimen AA45-2 failed by a major shear crack that zigzagged near the ends and around some of the AA plates and resulted in de-bonding of two AA plates near the point of application of the load as shown in Fig. 8(c).

\subsection{AADP Beam}

\subsubsection{Strength and Load-deflection response}

Fig. 9(a) shows the AADP specimen before testing. Specimen AADP was tested under fourpoint bending as well. The ultimate load capacity of specimen AADP was $109.55 \mathrm{kN}$ as shown in Table 6. Thus, there is an increase in the load carrying capacity of the strengthened AADP 
specimen over the CB specimen by $80.4 \%$. Fig. 9(b) shows the load-deflection response of AADP specimen. It was observed from the load-deflection curve of Fig. 9(b) that the deflection at ultimate load of specimen AADP was $\delta_{\mathrm{u}}=7.53 \mathrm{~mm}$.

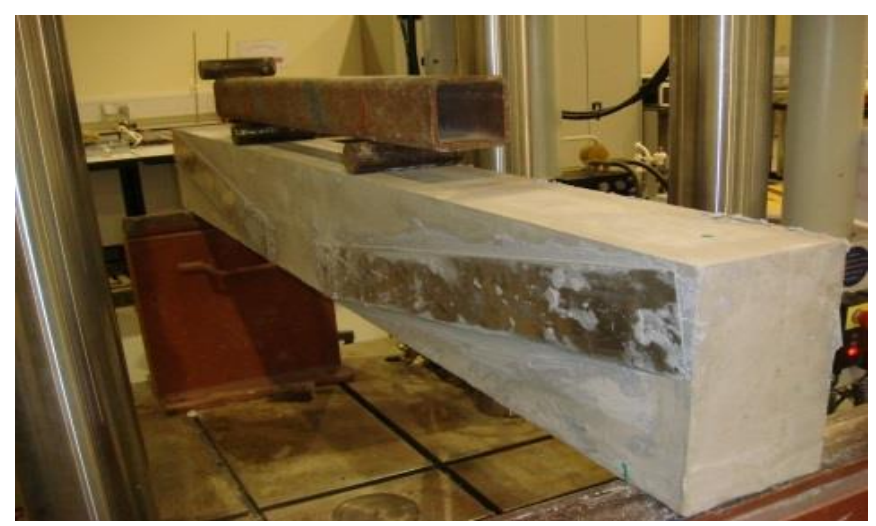

(a) Diagonal Plate bonded to the side -AADP
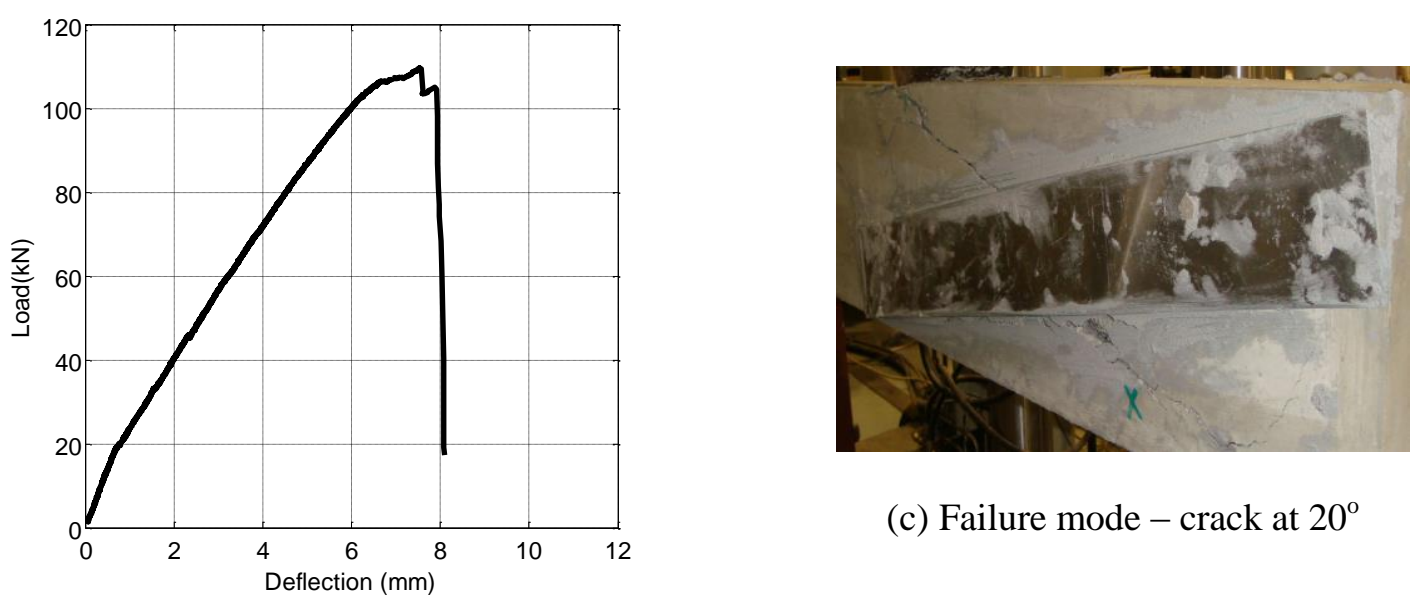

(c) Failure mode - crack at $20^{\circ}$

(b) Load-deflection for AADP

Fig. 9. Specimen with diagonal AA plate (AADP)

\subsubsection{Failure mechanism dicussion}

This beam's behavior was different from the other strengthened specimens (AA90 and AA45). As shown in Fig 9 (c), the beam failed by a truss action in a combined shear and flexural mode due to the diagonally bonded plates that acted as tension ties. The beam failed by a major diagonal shear crack, inclined at an angle of about $20^{\circ}$ as shown in Fig. 9(c), which is way smaller than the typical failure angle of $45^{\circ}$. The truss action created by the diagonal plates 
(tension ties) enhanced the beam's performance and resulted in higher load than the calculated beam flexural capacity of $98 \mathrm{kN}$ which is also higher than CB and AA90. Thus, such strengthening configuration of diagonally attached plates increased both the flexural and shear capacities of the RC beam specimen.

\subsection{Summary of results}

The load versus mid-span deflection curves of all tested specimens are plotted in Fig. 10. As presented earlier and summarized below, there is an increase in the load carrying capacity of AA strengthened beams ranging between $23.5 \%$ and $88.9 \%$. This verifies that the use of AA plates as an external reinforcement for concrete beams is highly effective technique in increasing the beam shear capacity. It has also achieved a decrease in shear cracks during the loading process. The highest increase was reached by the AA- 45 specimens which is a result of having the plates bonded perpendicular to the expected cracks' direction. In addition, AA-90 specimens and AADP beam achieved an average increase in the load carrying capacity of $49.7 \%$ and $80 \%$ respectively. 


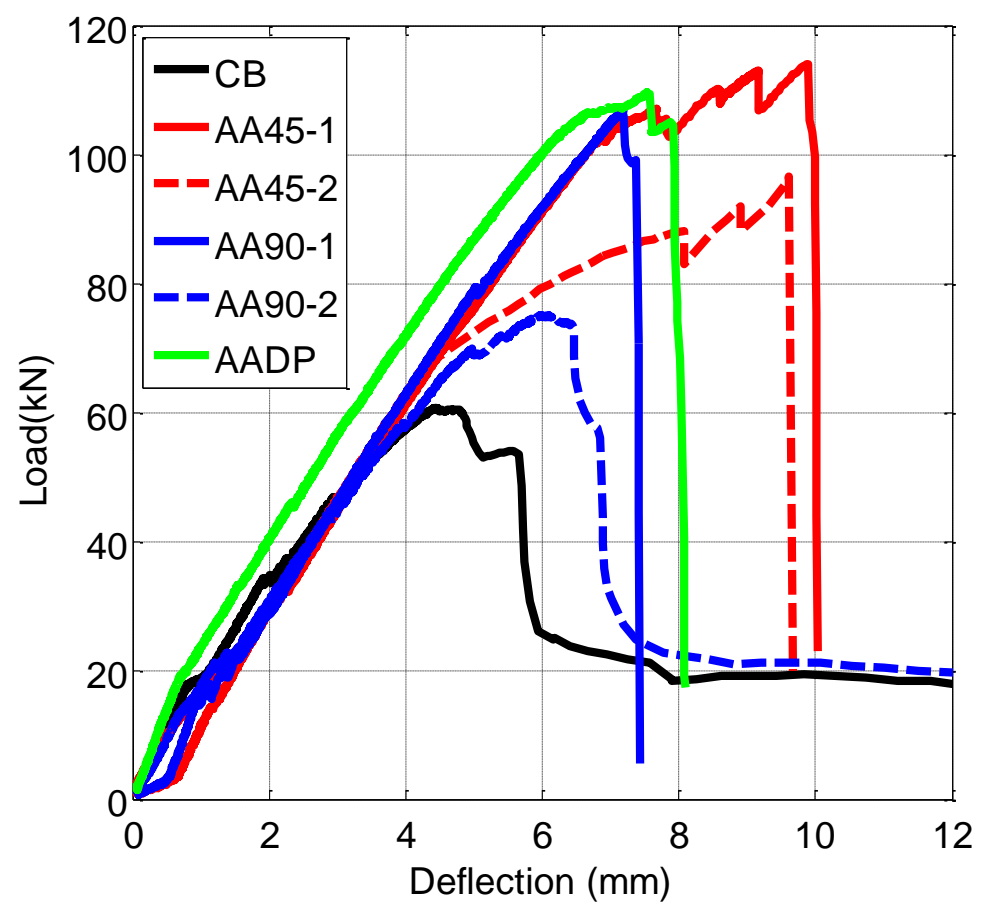

Fig. 10 Load vs deflection for all tested beams

It is worth mentioning that there is a considerable difference between the magnitude of the ultimate load of AA90-1 and AA90-2 and to some extent between that of AA45-1 and AA45-2. This difference is the result of: (1) the un-even surface roughness resulting from the un-even manual grinding of the AA plane surface; (2) the amount and thickness of the epoxy used to fill the un-even rough surfaces. The variation in AA surface roughness and the amount of epoxy used affected both the magnitude of the ultimate load and the failure mode of identical specimens. For consistent results, even grindings of the AA surface is needed and accordingly similar amount of epoxy can be maintained which will produce more consistent results. Such even surface roughness can be achieved by using a CNC machine for grinding or grooving. 


\section{Prediction of shear capacity using different FRP codes}

Many analytical models have been developed to predict the shear capacity of RC beams strengthened with FRP sheets, FRP plates, and steel plates. Equations developed by ACI 440 [49], FIB14 [50], the concrete society in the UK (TR55) [51] and the Simplified Modified Compression Field Theory (SMCFT) [52] codes for FRP plates will be applied to predict the shear capacity of the beams strengthened with AA plates. These equations will be applied on the specimens with AA plates oriented at angles of $90^{\circ}$ and $45^{\circ}$ from the beam's longitudinal axis and sample calculations will be presented for each equation.

\subsection{ACI 440 Predictions}

ACI 440.2R-08 [49] is the American guide for the design and construction of externally bonded FRP systems for strengthening concrete structures. Fig. 11 shows some of the dimensions and variables that are used in predicting the FRP contribution to the shear capacity of strengthened RC beams. Equation (1), which is developed for FRP, has been used to predict the shear strength of the RC beams strengthened with AA plates. The effective thickness of the AA plate is assumed to be equal to $1.5 \mathrm{~mm}$ because of the small reduction due to grinding.

$V_{n}=V_{c}+V_{s}+\Psi V_{f}$

$V_{c}=0.17 \sqrt{f_{c}^{\prime}} b_{w} d$

$V_{f}=\frac{A_{f v} f_{f e}(\sin \alpha+\cos \alpha) d_{f v}}{S_{f}}$

$$
\begin{aligned}
& A_{f v}=2 n t_{f} w_{f}=2(1)(1.5)(50)=150 \mathrm{~mm}^{2} \\
& k_{1}=\left(\frac{f_{c}^{\prime}}{27.6}\right)^{\frac{2}{3}}=\left(\frac{30}{27.6}\right)^{\frac{2}{3}}=1.0515
\end{aligned}
$$




$$
\begin{aligned}
& L_{e}=\frac{23300}{\left(n t_{f} E_{f}\right)^{0.58}}=\frac{23300}{(1 * 1.5 * 70000)^{0.58}}=28.51 \mathrm{~mm} \\
& k_{2}=\frac{d_{f v}-2 L_{e}}{d_{f v}}=\frac{190-2(28.51)}{190}=0.6998 \\
& k_{v}=\frac{k_{1} k_{2} L_{e}}{11900 \varepsilon_{f u}}=\frac{(1.0515)(0.6998)(28.51)}{11900 *(146.3 / 70000)}=0.8436 \leq 0.75 \rightarrow k_{v}=0.75 \\
& \varepsilon_{f e}=k_{v} \varepsilon_{f u}=0.75(146.3 / 70000)=0.0015675 \leq 0.004 \\
& f_{f e}=\varepsilon_{f e} E_{f}=0.0015675(70000)=109.725 \mathrm{MPa} \\
& V_{f}=\frac{A_{f v} f_{f e}(\sin \alpha+\cos \alpha) d_{f v}}{S_{f}}=\frac{150(109.725) *(\sin 1.5707+\cos 1.5707)(190)}{(128)}=24.43 \mathrm{kN} \\
& V_{c}=0.17 \sqrt{f_{c}^{\prime}} b_{w} d=0.17 \sqrt{29.76} * 150 * 200=27.82 \\
& V_{n}=V_{c}+V_{s}+\Psi V_{f}=27.82+0+(1)(24.43)=52.25 \mathrm{kN} \\
& P_{n}=2 V_{n}=2 * 52.25=104.5 \mathrm{kN}
\end{aligned}
$$

where,

$V_{f} \quad$ nominal shear strength provided by FRP plates (N)

$V_{c} \quad$ nominal shear strength provided by concrete $(\mathrm{N})$

$V_{s} \quad$ nominal shear strength provided by shear reinforcement $(\mathrm{N})$

$\Psi_{f} \quad$ additional FRP strength-reduction factor

$A_{f v} \quad$ area of FRP shear reinforcement with spacing $\mathrm{s},\left(\mathrm{mm}^{2}\right)$

$f_{f e} \quad$ effective stress in the FRP; stress level attained at section failure, (MPa)

$d_{f v} \quad$ effective depth of the FRP shear reinforcement, (mm)

$\varepsilon_{f e} \quad$ effective strain level in FRP reinforcement attained at failure, $(\mathrm{mm} / \mathrm{mm})$ 
$L_{e} \quad$ active bond length of FRP laminates, (mm)

$\varepsilon_{f u} \quad$ ultimate rupture strain of FRP reinforcement, $(\mathrm{mm} / \mathrm{mm})$

$E_{f} \quad$ tensile modulus of elasticity of FRP plates, (MPa)

$n \quad$ number of plies of FRP reinforcement

$b_{w} \quad$ web width or diameter of circular section, $(\mathrm{mm})$

$w_{f} \quad$ width of FRP reinforcing plies, (mm)

$t_{f} \quad$ nominal thickness of one ply of FRP reinforcment, (mm)
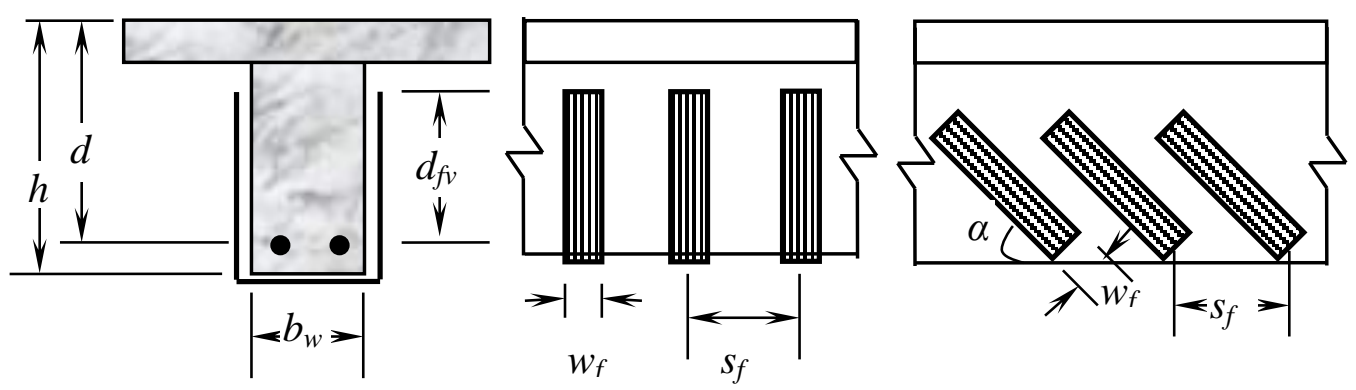

Fig. 11. Dimensional variables for externally bonded FRP [48]

\subsection{International federation of structural concrete (FIB 14) Predictions}

International federation of structural concrete (FIB 14) [50] explains the design and use of externally bonded fiber reinforced polymer reinforcement (FRP EBR) for reinforced concrete structures. According to FIB14, the following design guidelines are recommended to calculate the FRP contribution to the shear capacity of RC beams. The shear strength of reinforced concrete beams externally strengthened with FRP laminates is calculated using Eq. 4 according to the FIB14 design guidelines.

$V_{R d}=V_{c d}+V_{w d}+V_{f d}$ 
$V_{f d}=0.9 \varepsilon_{f d, e} E_{f u} \rho_{f} b_{w} d(\cot \theta+\cot \alpha) \sin \alpha$

$$
\begin{aligned}
& \rho_{f}=\left(\frac{2 t_{f}}{b_{w}}\right)\left(\frac{b_{f}}{s_{f}}\right)=\left(\frac{2 * 1.5}{150}\right)\left(\frac{50}{128}\right)=0.0078125 \\
& \varepsilon_{f e}=\min \left\{\left(0.65\left(\frac{\left(f_{c m}\right)^{2 / 3}}{E_{f u} \rho_{f}}\right)^{0.56}\right) \times 10^{-3} \text { or } 0.17\left(\frac{\left(f_{c m}\right)^{2 / 3}}{E_{f u} \rho_{f}}\right)^{0.3} \varepsilon_{f u}\right\}
\end{aligned}
$$

Since no fracture occurred, the first part of the equation applied

$$
=\left[0.65\left(\frac{(37.2)^{2 / 3}}{70 * 0.0078125}\right)^{0.56}\right] \times 10^{-3}=0.003516
$$

Assuming $k=0.8$ and $\gamma_{f}=1.5$

$\varepsilon_{f d, e}=0.8 * 0.0035156 / 1.5=0.001875$

$\cot \theta=\cot 45=1$

$\cot \alpha=\cot 90=0$

$\sin \alpha=\sin 90=1$

$V_{f d}=0.9 \varepsilon_{f d, e} E_{f u} \rho_{f} b_{w} d(\cot \theta+\cot \alpha) \sin \alpha$

$=0.9(0.001875)(70000)(0.0078125)(150)(200)(1+0) * 1=27.685 \mathrm{kN}$

$V_{R d}=V_{c d}+V_{w d}+V_{f d}=27.82+27.685=55.505 \mathrm{kN}$

$P_{n}=2 * V_{R d}=2 * 55.505=111.01 \mathrm{kN}$

where,

$V_{f d} \quad$ FRP contribution to shear capacity

$V_{c d} \quad$ concrete contribution to shear capacity

$\varepsilon_{f d, e} \quad$ design value of the effective FRP strain 
$E_{f u} \quad$ elastic modulus of FRP in the principle fiber orientation

$\rho_{f} \quad$ FRP reinforcement ratio equal to $\frac{2 t_{f} \sin \alpha}{b_{w}}$ for continuously bonded shear reinforcement

or $\left(\frac{2 t_{f}}{b_{w}}\right)\left(\frac{b_{f}}{s_{f}}\right)$ for FRP reinforcement in the form of strips

$b_{w} \quad$ minimum width of cross section over the effective depth

$b_{f} \quad$ width of the strips of the bonded reinforcment $(\mathrm{mm})$

$s_{f} \quad$ spacing between the strips of the bodned reiforcment $(\mathrm{mm})$

$t_{f} \quad$ thickness of bonded reinforcment (mm)

$d \quad$ effective depth of cross section (mm)

$\theta \quad$ angle of diagonal crack with respect to the member axis, assumed equal to $45^{\circ}$

$\alpha \quad$ angle between principal fibre orientation and longitudinal axis of member

$k \quad$ reduction factor $(\mathrm{k}=0.8)$

$\gamma_{w}=\gamma_{f b}$ partial safety factor (if failure involves fracture)

\subsection{The concrete society in the UK (TR55)}

TR55 [51] is the design guidance for strengthening concrete structures using fiber composite materials in UK. Equation 6 is used to predict the shear strength of RC beams externally strengthened with FRP sheets and plates according to the TR55 design guidelines. Details of the elements of this equation are given in TR55.

$$
\begin{aligned}
& V_{\mathrm{Re}}=V_{R c}+V_{R I}+V_{R f} \\
& V_{R f}=\left(\frac{1}{\gamma_{m F}}\right) A_{f s}\left(E_{f d} \varepsilon_{f e}\right) \sin \beta(1+\cot \beta)\left(\frac{d_{f}}{S_{f}}\right)
\end{aligned}
$$




$$
\begin{aligned}
& \rho_{f}=\left(\frac{2 t_{f}}{b_{w}}\right)\left(\frac{b_{f}}{s_{f}}\right)=\left(\frac{2 * 1.5}{150}\right)\left(\frac{50}{128}\right)=0.0078125 \\
& L_{e}=\frac{461.3}{\left(t_{f} E_{f d}\right)^{0.58}}=\frac{461.3}{(1.5 * 70)^{0.58}}=31.024 \\
& w_{f e}=d_{f}-2 L_{e}=200-2 * 31.024=137.95 \\
& A_{f s}=2 t_{f} w_{f e}=2 * 1.5 * 137.95=413.858
\end{aligned}
$$

Assuming $\gamma_{m f}=1$

$$
\begin{aligned}
& \varepsilon_{f u}=\frac{\varepsilon_{f k}}{\gamma_{m f}}=\frac{(146.3 / 70000)}{1}=0.00209 \\
& \left.\varepsilon_{f e}=\varepsilon_{f u} \mid 0.5622\left(\rho_{f} E_{f d}\right)^{2}-1.2188 \rho_{f} E_{f d}+0.778\right] \\
& =(146.3 / 70000) *\left[0.5622(0.0078125 * 71)^{2} 1.2188 * 0.0078125 * 70+0.778\right]=0.000584 \\
& \varepsilon_{f e}=\frac{0.0042\left[0.835\left(f_{c u}\right)^{2 / 3}\right] \times w_{f e}}{\left(E_{f d} t_{f}\right)^{0.58} \times d}=\frac{0.0042\left[0.835(37.2)^{2 / 3}\right] \times 137.95}{(70 * 1.5)^{0.58} \times 200}=0.001813 \\
& V_{R f}=\left(\frac{1}{\gamma_{m F}}\right) A_{f s}\left(E_{f d} \varepsilon_{f e}\right) \sin \beta(1+\cot \beta)\left(\frac{d_{f}}{S_{f}}\right) \\
& =\left(\frac{1}{1}\right)(413.858)(70 * 0.000584) \sin 90(1+\cot 90)\left(\frac{200}{128}\right)=26.45 \mathrm{kN} \\
& P_{n}=2 * V_{R d}=2 * 54.27=108.55 \mathrm{kN} \\
& V_{\mathrm{Re}}=V_{R c}+V_{R I}+V_{R f}=27.82+26.45=54.27 \mathrm{kN}
\end{aligned}
$$

Where,

$V_{R f} \quad$ FRP contribution to shear capacity

$V_{R c} \quad$ concrete contribution to shear capacity

$A_{f s} \quad$ area of FRP shear reinforcement

$E_{f d}$ design Elastic modulus of FRP $(\mathrm{GPa})$ 
$\varepsilon_{f u} \quad$ design ultimate failure strain in FRP

$w_{f e} \quad$ effective width of the FRP

$s_{f} \quad$ spacing between the strips of the bodned reiforcment $(\mathrm{mm})$

$\rho_{f} \quad$ FRP reinforcement ratio equal to $\frac{2 t_{f} \sin \alpha}{b_{w}}$ for continuously bonded shear reinforcement

or $\left(\frac{2 t_{f}}{b_{w}}\right)\left(\frac{b_{f}}{s_{f}}\right)$ for FRP reinforcement in the form of strips

$b_{w} \quad$ minimum width of cross section over the effective depth

$w_{f} \quad$ width of the strips of the bonded reinforcment $(\mathrm{mm})$

$s_{f} \quad$ spacing between the strips of the bonded reinforcement $(\mathrm{mm})$

$t_{f} \quad$ thickness of bonded reinforcement $(\mathrm{mm})$

$d \quad$ effective depth of cross section (mm)

$f_{c u} \quad$ cube strength of concrete (MPa)

$\beta \quad$ angle between principal fibre orientation and longitudinal axis of member

$\gamma_{m F} \quad$ partail saftey factor for FRP

\subsection{Simplified Modified Compression Field Theory Predictions:}

The Simplified Modified Compression Field Theory (SMCFT), originally developed by Bentz et al. [52] and adopted by AASHTO LRFD 2014, is used here as presented in Eq. 7 to predict the shear capacity of the reinforced concrete beams strengthened in shear with AA plates.

An iterative procedure is required to perform the calculations of the SMCFT. The initial estimates of $V_{c}$ and $V_{A A}$ are determined from the ACI 318-14 equations of $V_{c}$ and $V_{s}$ respectively. Once the shear capacity of the section is calculated $\left(V_{n}\right)$, the strain in the steel $\left(\varepsilon_{\mathrm{s}}\right)$ is 
computed. Once determined, $\left(\varepsilon_{\mathrm{s}}\right)$ is used to compute $\beta$ and $\theta$. These two quantities are then used to update the $V_{c}$ and $V_{A A}$ then $V_{n}$. The process is then repeated until the solution converges to the correct $V_{n}$. The debonding strain of an FRP sheet or plate is estimated based on the ACI440.2R08 suggested values of the lesser of 0.004 and $0.75 \varepsilon_{f u}$. Since the AA plate does not show signs of yielding upon shear failure, the rupture strain $\varepsilon_{f u}$ of FRP is replaced with the yielding strain of the AA plate $\varepsilon_{y A A}$. Accordingly, the debonding strain of the AA plate is estimated to $0.75 \varepsilon_{y A A}=$ $0.75 \times 0.0021=0.001575$. Furthermore, the effective thickness of the AA plate is assumed to be equal to $1.5 \mathrm{~mm}$ because of the small reduction due to grinding. Below, the SMCFT equations are given along with the calculations to predict the capacity of the AA90 specimen in order to demonstrate the analytical prediction procedure. Calculations will be given for the last iteration at convergence in case the shear crack forms at the most critical section under the point load at the section of maximum moment.

$$
\begin{gathered}
V_{n}=V_{C}+V_{S}+V_{A A} \\
V_{A A}=\frac{A_{v} f_{e A A} d_{v}(\cot \theta+\cot \alpha) \sin \alpha}{S} \\
V_{C}=\beta \sqrt{f_{c}^{\prime}} b_{v} d_{v} \\
\varepsilon_{s}=\frac{\frac{|M|}{d_{v}}+0.5 N+V_{n}}{A_{s} E_{s}}=0.002653 \\
\beta=\frac{0.4}{1+750 \varepsilon_{s}} \frac{1300}{1000+s_{x e}}=0.1509 \\
\theta=\left(29^{\circ}+3500 \varepsilon_{s}\right)=38.28^{\circ} \\
S_{x e}=S_{x} \frac{35}{a_{g}+16}=153 \mathrm{~mm}
\end{gathered}
$$




$$
\begin{gathered}
d_{v}=\text { Maximum }\left(\begin{array}{l}
0.72 h=180 \mathrm{~mm} \\
0.9 d=180 \mathrm{~mm} \\
M_{n} / A_{y} f_{y}=168.7 \mathrm{~mm}
\end{array}\right)=180 \mathrm{~mm} \\
V_{C}=\beta \sqrt{f_{c}^{\prime}} b_{v} d_{v}=22.22 \mathrm{kN} \\
V_{S}=\frac{A_{v} f_{y} d_{v}(\cot \theta+\cot \alpha) \sin \alpha}{S}=0 \\
V_{A A}=\frac{A_{v} f_{e A A} d_{v}(\cot \theta+\cot \alpha) \sin \alpha}{S}=29.46 \mathrm{kN} \\
V_{n}=V_{C}+V_{S}+V_{A A}=22.22+0+29.46=51.68 \mathrm{kN} \\
P_{n}=2 V_{n}=103.37 \mathrm{kN}
\end{gathered}
$$

Where

$d_{v}=$ effective shear depth taken as the distance, measured perpendicular to the neutral axis, between the tensile resultant and compressive force due to flexure. It needs not be taken to be less than the greater of $0.9 \mathrm{~d}$ or $0.72 \mathrm{~h}$.

$\beta=$ factor indicating ability of diagonally cracked concrete to transmit tension and shear $\theta=$ angle of inclination of diagonal compressive stresses or shear crack $\left(^{\circ}\right)$ $\alpha=$ angle of inclination of transverse reinforcement to longitudinal axis $\left({ }^{\circ}\right)$. $S_{x}=$ the lesser of $\mathrm{dv}$ or the vertical distance between horizontal layers of longitudinal crack control reinforcement.

$a_{g}=$ maximum aggregate size and it has to equal zero when $f_{c}^{\prime} \geq 69 M P a$ $M=$ moment in N.mm $V=$ shear force in Newton $N=$ axial force, taken as positive if tensile and negative if compressive in Newton 
$A_{s}=$ area of non-prestressed steel on the flexural tension side of the section. This is considered to be the area of flexural reinforcement under the original geometric centroid of the section. $E_{s}=$ modulus of elasticity of steel in ksi (MPa).

According to this theory, the control beam is predicted to have $\mathrm{V}_{\mathrm{n}}=\mathrm{V}_{\mathrm{c}}=31.93 \mathrm{kN}$ when the shear crack is initiated at the loading point near mid-span. This corresponds to $P_{n}=63.86 \mathrm{kN}$ which is comparable to the $60.73 \mathrm{kN}$ ultimate load.

For the beam AA-90, it is predicted to have $\mathrm{V}_{\mathrm{n}}=\mathrm{V}_{\mathrm{c}}+\mathrm{V}_{\mathrm{AA}}=51.68 \mathrm{kN}$ when the shear crack starts at the loading point near mid-span. This corresponds to $P_{n}=103.37 \mathrm{kN}$ which is slightly lower than the $106.94 \mathrm{kN}$ ultimate load of Beam AA-90-1. On the other hand, Beam AA90-2 failed prematurely at $75 \mathrm{kN}$ which may be attributed to thinner AA plate thickness due to the manual grinding.

For the Beam AA-45, it is predicted to have $V_{n}=V_{c}+V_{A A}=57.27 \mathrm{kN}$ when the shear crack starts at the loading point near mid-span. This corresponds to $P_{n}=114.55 \mathrm{kN}$ which is matching the ultimate load of Beam AA-45-1 that failed at $114.74 \mathrm{kN}$. On the other hand, the failure load of Beam AA-45-2 is found to be $96.75 \mathrm{kN}$. This reduction in ultimate load may also be attributed to thinner AA plate thickness due to the manual grinding. In general the SMCFT is found to accurate enough in prediction the ultimate shear capacity of the strengthened beams.

\subsection{Summary of the results}

The four shear strength prediction code equations were used to predict the shear capacity of concrete sections and hence compute the ultimate shear strength of the tested specimens. Table 7 and Fig. 12 show the results of the statistical measurements of the predictions of the ACI, TR55, FIB14 and SMCFT codes. The ultimate predicted load $\left(\mathrm{P}_{\mathrm{pre}}\right)$ is equal to twice the shear capacity of the reinforced concrete beam predicted by one of the codes such as $V_{n}$ in ACI440 and 
Published in Construction and Building Materials, Vol. 128, 2016, pp. 24-37.

SMCFT, $V_{\mathrm{Rd}}$ in FIB14 or $\mathrm{V}_{\mathrm{Re}}$ in TR55. The recommended additional reduction factor $\left(\Psi_{f}\right)$ in the ACI equation was assumed to be 1.0 since the values suggested in the code are based on a reliability analysis of FRP data. Similarly in TR55 predictions, the partial safety factor $\left(\gamma_{\mathrm{f}}=\gamma_{\mathrm{fb}}\right)$ was not applied since the values suggest are based on the FRP laminates mechanical of properties and method of manufacture. For the FIB14 predictions, a material safety factor of 1.5 was applied for the concrete since the bond failure occurred in the concrete. Further investigation is required for the safety factors applied in each code for the AA plates contribution is the shear capacity of the RC beams.

As observed, the Mean Absolute Percent Error (MAPE) of the prediction by each of the four codes is relatively comparable with maximum MAPE of $48.78 \%$ depicted by FIB14 prediction for specimen AA90-2. The average of MAPE for all code predictions ranges between $14.94 \%$ and $27.45 \%$ which indicates that they have comparable accuracy, with the SMCFT appears to be the most accurate and the FIB14 is the least accurate in predicting the shear strength of the tested beams.

Table 7 Measured and predicted ultimate loads of AA90 and AA45 Specimens

\begin{tabular}{|c|c|c|c|c|c|c|c|c|c|c|c|c|c|}
\hline & & \multicolumn{3}{|c|}{ ACI 440 [49] } & \multicolumn{3}{|c|}{ FIB $14[50]$} & \multicolumn{3}{|c|}{ TR55 [51] } & \multicolumn{3}{|c|}{ SMCFT [52] } \\
\hline Specimen & $\begin{array}{c}\text { Measured } \\
\text { (Exp.) } \\
(\mathrm{kN})\end{array}$ & $\begin{array}{l}\text { Pred. } \\
\left(\psi_{\mathrm{f}}=1\right) \\
(\mathrm{kN})\end{array}$ & $\begin{array}{l}\mathrm{P}_{\text {exp }} / \\
\mathrm{P}_{\text {pre }}\end{array}$ & $\begin{array}{c}\text { MAPE } \\
(\%)\end{array}$ & $\begin{array}{c}\text { Pred. } \\
(\mathrm{No} k) \\
(\mathrm{kN})\end{array}$ & $\begin{array}{l}\mathrm{P}_{\text {exp }} / \\
\mathrm{P}_{\text {pre }}\end{array}$ & $\begin{array}{c}\text { MAPE } \\
(\%)\end{array}$ & $\begin{array}{l}\text { Pred } \\
(3.5) \\
(\mathrm{kN})\end{array}$ & $\begin{array}{l}\mathrm{P}_{\text {exp }} / \\
\mathrm{P}_{\text {pre }}\end{array}$ & $\begin{array}{c}\text { MAPE } \\
(\%)\end{array}$ & $\begin{array}{l}\text { Pred. } \\
(\mathrm{kN})\end{array}$ & $\begin{array}{c}\mathrm{P}_{\text {exp }} / \\
\mathrm{P}_{\text {pre }}\end{array}$ & $\begin{array}{c}\text { MAPE } \\
(\%)\end{array}$ \\
\hline AA90-1 & 106.83 & 104.51 & 1.02 & 1.75 & 111.02 & 0.96 & 4.49 & 108.55 & 0.99 & 1.40 & 103.37 & 1.03 & 3.24 \\
\hline AA90-2 & 75.03 & 104.51 & 0.71 & 39.90 & 111.02 & 0.67 & 48.78 & 108.55 & 0.69 & 44.38 & 103.37 & 0.73 & 37.77 \\
\hline AA45-1 & 114.74 & 124.74 & 0.92 & 9.20 & 133.96 & 0.85 & 17.35 & 130.46 & 0.88 & 13.35 & 114.55 & 1.00 & 0.17 \\
\hline AA45-2 & 96.75 & 124.74 & 0.77 & 29.51 & 133.96 & 0.72 & 39.17 & 130.46 & 0.74 & 34.43 & 114.55 & 0.84 & 18.59 \\
\hline Average & & & 0.86 & 20.09 & & 0.80 & 27.45 & & 0.83 & 23.39 & & 0.9 & 14.94 \\
\hline
\end{tabular}




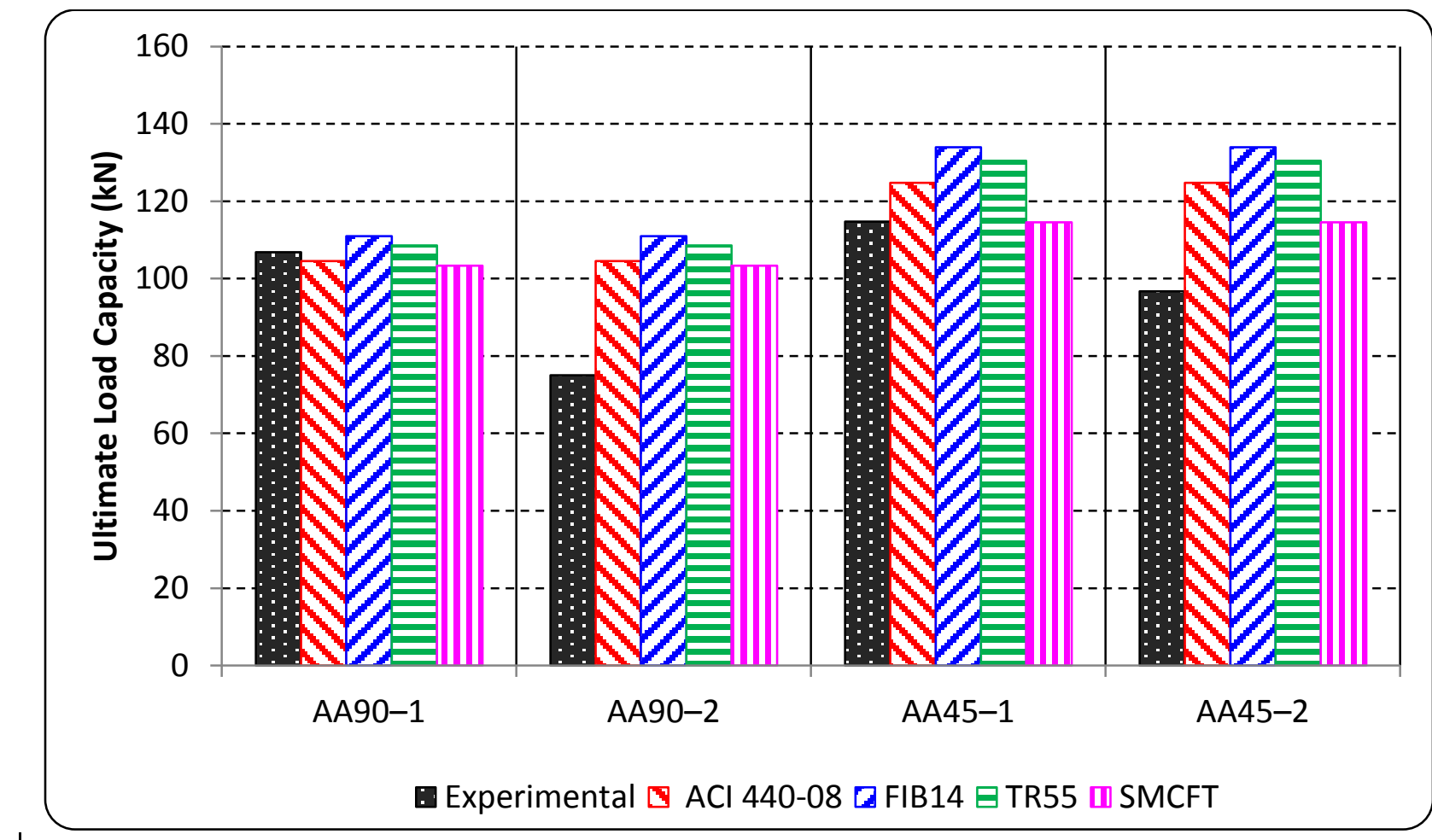

Fig. 12 Measured and predicted ultimate loads

\section{Conclusions}

This paper presents the result of five RC beams strengthened in shear with externally bonded AA plates with different orientations and spacing. Based on this investigation the following observations and conclusions can be made:

1. Aluminum alloy plates can be used to externally strengthen reinforced concrete beams in shear. Based on the result of this investigation, the increase in shear capacity ranged between $24 \%$ and $89 \%$. Therefore, using Aluminum plates is a highly effective technique in increasing the beam shear capacity.

2. Orientation of AA plates, as external strengthening material, has a major effect on the load-carrying capacity of the strengthened RC beams. As observed, the $45^{\circ}$ AA plate 
orientation is more effective than the $90^{\circ}$ plate orientation in increasing the beam's shear capacity. However, this conclusion is valid for gravity loads or loads applied vertically downward as is the case in this test setting.

3. Codes developed for FRP (ACI440, FIB14 and TR55, SMCFT) can be used to predict, to some degree of accuracy, the shear capacity of beams strengthened with externally bonded AA plates, however, more specialized equations need to be developed for AA. This requires further experimental studies.

4. The result of this investigation validates the viability of using AA plates as alternative to the prevailing FRP laminates and steel plate as externally bonded shear strengthening material.

5. Further experimental studies will be required to confirm the effectiveness of using bonded AA plates in shear strengthening and also to investigate the effect of different orientations, grades, and thicknesses of AA plates in shear strengthening of RC beams.

\section{Acknowledgement}

The support for the experimental part of the research presented in this paper had been provided by the American University of Sharjah. The support is gratefully acknowledged. The views and conclusions, expressed or implied, in this paper are those of the authors and should not be interpreted as those of the sponsor. We want to acknowledge Engineer Arshi Faridi and Ansari for their help in conducting the experimental program. 


\section{References}

[1] Adhikary, B. B., Mutsuyoshi, H., \& Sano, M. (2000). Shear strengthening of reinforced concrete beams using steel plates bonded on beam web: experiments and analysis. Construction and Building Materials, 14(5), 237-244.

[2] Al-Sulaimani, G. J., Sharif, A., Basunbul, I. A., Baluch, M. H., \& Ghaleb, B. N. (1994). Shear repair for reinforced concrete by fiberglass plate bonding. Structural Journal, 91(4), 458-464.

[3] Chajes, M. J., Januszka, T. F., Mertz, D. R., Thomson Jr, T. A., \& Finch Jr, W. W. (1995). Shear strengthening of reinforced concrete beams using externally applied composite fabrics. ACI Structural Journal, 92(3).

[4] Triantafillou, T. C. (1998). Shear strengthening of reinforced concrete beams using epoxybonded FRP composites. ACI Structural Journal, 95(2).

[5] Täljsten, B., \& Elfgren, L. (2000). Strengthening concrete beams for shear using CFRPmaterials: evaluation of different application methods. Composites Part B: Engineering, 31(2), 87-96.

[6] Khalifa, A., \& Nanni, A. (2000). Improving shear capacity of existing RC T-section beams using CFRP composites. Cement and Concrete Composites, 22(3), 165-174.

[7] Bakis, C., Bank, L. C., Brown, V., Cosenza, E., Davalos, J. F., Lesko, J. J.,\& Triantafillou, T. C. (2002). Fiber-reinforced polymer composites for construction-state-of-the-art review. Journal of Composites for Construction, 6(2), 73-87.

[8] Täljsten, B. (2003). Strengthening concrete beams for shear with CFRP sheets. Construction and Building Materials, 17(1), 15-26. 
Published in Construction and Building Materials, Vol. 128, 2016, pp. 24-37.

[9] Bousselham, A., \& Chaallal, O. (2004). Shear strengthening reinforced concrete beams with fiber-reinforced polymer: Assessment of influencing parameters and required research. $A C I$ Structural Journal, 101(2).

[10] Zhang, Z., \& Hsu, C. T. T. (2005). Shear strengthening of reinforced concrete beams using carbon-fiber-reinforced polymer laminates. Journal of Composites for Construction, 9(2), 158-169.

[11] Monti, G. (2007). Tests and design equations for FRP-strengthening in shear. Construction and Building Materials, 21(4), 799-809.

[12] Sundarraja, M. C., \& Rajamohan, S. (2009). Strengthening of RC beams in shear using GFRP inclined strips-An experimental study. Construction and building materials, 23(2), 856-864.

[13] Belarbi, A., Bae, S. W., \& Brancaccio, A. (2012). Behavior of full-scale RC T-beams strengthened in shear with externally bonded FRP sheets. Construction and Building Materials, 32, 27-40.

[14] Colalillo, M. A., \& Sheikh, S. A. (2012). Seismic retrofit of shear-critical reinforced concrete beams using CFRP. Construction and Building Materials, 32, 99-109.

[15] Dong, J. F., Wang, Q. Y., \& Guan, Z. W. (2012). Structural behaviour of RC beams externally strengthened with FRP sheets under fatigue and monotonic loading. Engineering Structures, 41, 24-33.

[16] Baggio, D., Soudki, K., \& Noël, M. (2014). Strengthening of shear critical RC beams with various FRP systems. Construction and Building Materials, 66, 634-644. 
[17] Mofidi, A., \& Chaallal, O. (2014). Tests and design provisions for reinforced-concrete beams strengthened in shear using FRP sheets and strips. International Journal of Concrete Structures and Materials, 8(2), 117-128.

[18] Baghi, H., Barros, J. A., Rezazadeh, M., \& Laranjeira, J. (2015). Shear Strengthening of Damaged RC Beams with Hybrid Composite Plates. Journal of Composites for Construction, 04015041.

[19] Panigrahi, A. K., Biswal, K. C., \& Barik, M. R. (2014). Strengthening of shear deficient RC T-beams with externally bonded GFRP sheets. Construction and Building Materials, 57, 8191.

[20] Li, A., Assih, J., \& Delmas, Y. (2001). Shear strengthening of RC beams with externally bonded CFRP sheets. Journal of Structural Engineering,127(4), 374-380.

[21] Aykac, S., Kalkan, I., Aykac, B., Karahan, S., \& Kayar, S. (2012). Strengthening and repair of reinforced concrete beams using external steel plates. Journal of Structural Engineering, 139(6), 929-939.

[22] Barnes, R. A., Baglin, P. S., Mays, G. C., \& Subedi, N. K. (2001). External steel plate systems for the shear strengthening of reinforced concrete beams. Engineering structures, 23(9), 1162-1176.

[23] Adhikary, B. B., \& Mutsuyoshi, H. (2006). Shear strengthening of RC beams with webbonded continuous steel plates. Construction and Building Materials, 20(5), 296-307.

[24] Adhikary, B. B., \& Mutsuyoshi, H. (2006). Shear strengthening of reinforced concrete beams using various techniques. Construction and Building Materials, 20(6), 366-373. 
[25] Barnes, R. A., \& Mays, G. C. (2006). Strengthening of reinforced concrete beams in shear by the use of externally bonded steel plates: Part 1-Experimental program. Construction and Building Materials, 20(6), 396-402.

[26] Abdalla, J.A., Abu-Obeidah, A. and Hawileh, R.A. (2011). Behavior of Shear Deficient Reinforced Concrete Beams with Externally Bonded Aluminum Alloy Plates. The 2011 World Congress on Advances in Structural Engineering and Mechanics (ASEMI'11+ Congress, Seoul, South Korea, September 18- 23.

[27] Abu-Obeidah, A., Hawileh, R. A., and Abdalla, J. A. (2012), "Finite Element Modeling of Shear Deficient Beams Bonded with Aluminum Plates." Proceedings of the $11^{\text {th }}$ International Conference on Computational Structures Technology, Civil-Comp Press, Stirlingshire, Scotland, paper 1, 2012, Dubrovnik, Croatia, September 4-9.

[28] Abu-Obeidah, A., Hawileh, R. A. and Abdalla, J. A. (2015). Finite element analysis of strengthened RC beams in shear with aluminum plates. Computers \& Structures, 147, 36-46.

[29] Chaallal, O., Nollet, M. J., \& Perraton, D. (1998). Shear strengthening of RC beams by externally bonded side CFRP strips. Journal of Composites for Construction, 2(2), 111-113.

[30] Grace, N. F., Sayed, G. A., Soliman, A. K., \& Saleh, K. R. (1999). Strengthening reinforced concrete beams using fiber reinforced polymer (FRP) laminates. ACI Structural Journal, 96(5), 865-875.

[31] Sim, J., Kim, G., Park, C., \& Ju, M. (2005). Shear strengthening effects with varying types of FRP materials and strengthening methods. ACI Special Publication, 230.

[32] Hawileh, R.A., Nawaz, W., Abdalla, J.A. and Saqan, E.I. (2015). Effect of Flexural CFRP Sheets on Shear Resistance of Reinforced Concrete Beams. Composite Structures, Vol. 122, pp. 468-476. 
[33] Hawileh, R., Nawaz, W., Abdalla, J., and Saqan, E. (2015). External Strengthening of Shear Deficient Reinforced Concrete Beams with Flexural CFRP Laminates." Response of Structures under Extreme Loading, Proceedings of the $5^{\text {th }}$ International Workshop on Performance, Protection \& Strengthening of Structures under Extreme Loading (PROTECT 2015), pp. 368-373, East Lansing, Michigan, June 28-30.

[34] Nawaz, W., Hawileh, R.A., Saqan, E.I. and Abdalla, J.A. (2016). Effect of Longitudinal CFRP Plates on the Shear Strength of RC Beams. ACI Structural Journal, 113(3), 577586.

[35] Sato, Y., Ueda, T., Kakuta, Y., \& Tanaka, T. (1996). Shear reinforcing effect of carbon fiber sheet attached to side of reinforced concrete beams. In Proceedings of the 2nd International Conference on Advanced Composite Materials in Bridges and Structures, ACMBS-II, Montreal 1996.

[36] Umezu, K., Fujita, M., Nakai, H., \& Tamaki, K. (1997). Shear behavior of RC beams with aramid fiber sheet non-metallic (FRP) reinforcement for concrete structures. Proceedings of the 3rd International Symposium on Non-Metallic (FRP) Reinforcement for Concrete Structures, October 14-16, 1997, Tokyo, Japan, pp: 491-498.

[37] Mofidi, A., Chaallal, O., Benmokrane, B., \& Neale, K. (2011). Performance of endanchorage systems for RC beams strengthened in shear with epoxy-bonded FRP. Journal of Composites for Construction, 16(3), 322-331.

[38] Altin, S., Anil, Ö., \& Kara, M. E. (2005). Improving shear capacity of existing RC beams using external bonding of steel plates. Engineering structures, 27(5), 781-791.

[39] Kissell, J. R., \& Ferry, R. L. (1995). Aluminum structures: a guide to their specifications and design. 1st ed. New York, United States. John Wiley \& Sons. 
Published in Construction and Building Materials, Vol. 128, 2016, pp. 24-37.

[40] Dursun, T. and Soutis, C. (2014). Recent developments in advanced aircraft aluminium alloys. Materials \& Design, 56, 862-871.

[41] Mazzolani, F. and Feder M. (1995). Aluminium Alloy Structures, Second Edition: Publisher E \& FN Spon.

[42] Mazzolani, F. (2006). Structural Applications of Aluminium in Civil Engineering. Structural Engineering International 16(4), 280-285.

[43] Soetens, F. (2010). Aluminium Structures in Building and Civil Engineering Applications, Structural Engineering International 20(4), 430-435.

[44] Aluminum and Aluminum Alloys. Edited by Joseph R. Davis. ASM Speciality Handbook, 1993.

[45] Aalco. (n.d.). Retrieved January 15, 2011, from http://www.aalco.co.uk/datasheets

[46] Abdalla, J., Hraibb, F., Hawileha R., and Mirghania A. (2016). Experimental investigation of bond-slip behavior of aluminum plates adhesively bonded to concrete. Journal of Adhesion Science and Technology, DOI:10.1080/01694243.2016.1204741

[47] ASTM Standard B928/B928M, (2002). Standard Specification for High Magnesium Aluminum-Alloy Products for Marine Service and Similar Environments. ASTM International, West Conshohocken, PA, 2002, www.astm.org.

[48] Sika Construction Chemicals, Sikadur-30 LP, (2009). Adhesive for Bonding Reinforecment. Product Data Sheet, Sika Limited (Vietnam).

[49] ACI, ACI 440.2-08: Guide for the Design and Construction of Externally Bonded FRP Systems for Strengthening Concrete Structures," Farmington Hills, MI, 2008. 
Published in Construction and Building Materials, Vol. 128, 2016, pp. 24-37.

[50] FIB14 (2001). Externally bonded FRP reinforcement for RC structures. The international federation for structural concrete (CEB-FIB), technical report bulletin 14, Sika Services AG, Switzerland, 2001.

[51] TR55 (2000). Design guidance for strengthening concrete structures using fibre composite materials. Concrete Society.

[52] Bentz EC, Vecchio FJ, and Collins MP (2006). Simplified Modified Compression Field Theory for Calculating Shear Strength of Reinforced Concrete Elements. ACI Structural Journal 103(4), 614-624.

(C) 2016. This manuscript version is made available under the CC-BY-NCND 4.0 license http://creativecommons.org/licenses/by-nc-nd/4.0/ 